\title{
Greenland annual accumulation along the EGIG line, 1959-2004, from ASIRAS airborne radar and neutron-probe density measurements
}

\author{
Thomas B. Overly ${ }^{1}$, Robert L. Hawley ${ }^{1}$, Veit Helm ${ }^{3}$, Elizabeth M. Morris ${ }^{2}$, and Rohan N. Chaudhary ${ }^{1}$ \\ ${ }^{1}$ Dartmouth College, Hanover, NH, USA \\ ${ }^{2}$ Scott Polar Research Institute, Cambridge, UK \\ ${ }^{3}$ Alfred Wegener Institute, Bremerhaven, Germany \\ Correspondence to: Thomas B. Overly (thomas.b.overly@dartmouth.edu)
}

Received: 1 September 2015 - Published in The Cryosphere Discuss.: 14 December 2015

Revised: 21 June 2016 - Accepted: 21 June 2016 - Published: 2 August 2016

\begin{abstract}
We report annual snow accumulation rates from 1959 to 2004 along a $250 \mathrm{~km}$ segment of the Expéditions Glaciologiques Internationales au Groenland (EGIG) line across central Greenland using Airborne SAR/Interferometric Radar Altimeter System (ASIRAS) radar layers and high resolution neutron-probe (NP) density profiles. ASIRAS-NP-derived accumulation rates are not statistically different (95\% confidence interval) from in situ EGIG accumulation measurements from 1985 to 2004. ASIRAS-NP-derived accumulation increases by $20 \%$ below $3000 \mathrm{~m}$ elevation, and increases by $13 \%$ above $3000 \mathrm{~m}$ elevation for the period 1995 to 2004 compared to 1985 to 1994. Three Regional Climate Models (PolarMM5, RACMO2.3, MAR) underestimate snow accumulation below $3000 \mathrm{~m}$ by 16-20\% compared to ASIRAS-NP from 1985 to 2004. We test radar-derived accumulation rates sensitivity to density using modeled density profiles in place of NP densities. ASIRAS radar layers combined with Herron and Langway (1980) model density profiles (ASIRAS-HL) produce accumulation rates within $3.5 \%$ of ASIRAS-NP estimates in the dry snow region. We suggest using Herron and Langway (1980) density profiles to calibrate radar layers detected in dry snow regions of ice sheets lacking detailed in situ density measurements, such as those observed by the Operation IceBridge campaign.
\end{abstract}

\section{Introduction}

Estimating ice sheet mass balance requires knowledge of the gains and losses to the system. The IPCC estimates a $0.40 \pm 0.15 \mathrm{~m}$ sea-level rise by the year 2100 (scenario RCP2.6 IPCC, 2014). Assumptions in assessing snow accumulation (the primary positive input to ice sheets) account for a portion of the uncertainty in potential sea-level rise. Studies using ice cores (Anklin and Stauffer, 1994; Bales et al., 2001, 2009; Banta and McConnell, 2007; McConnell et al., 2001; Mosley-Thompson et al., 2001) provide records of past accumulation, while climate models (Box et al., 2004; Bromwich et al., 2001; Burgess et al., 2010; McConnell et al., 2000) reconstruct accumulation in regions lacking in situ measurements. Regional Climate Models (RCMs) provide widespread spatial coverage of recent annual snow accumulation (1958-2015), but these estimates interpolate between ground-truthed point locations (Burgess et al., 2010; Noël et al., 2015; Tedesco et al., 2015). The simplification of accumulation rates from point-based measurements may be overcome using ice-penetrating radar. Radar stratigraphy studies (Arcone et al., 2004, 2005; Eisen et al., 2008; Hawley et al., 2006, 2014; de la Pena et al., 2010; Spikes et al., 2004; Medley et al., 2013, 2014) measure snow accumulation by combining in situ measurements (snow density, ice core chemistry) with continuous isochronal layers within the dry-snow zone of ice sheets. The depth of a given radar layer depends on the density of the snowpack through which the radar signal travels. Using density to calculate the depth and age of these layers allows for the estimation of an accumula- 
tion rate. Given this density and signal propagation relationship, we assume that the most accurate radar-derived snow accumulation rates result from radar surveys collected simultaneously with in situ density measurements.

The European Space Agency's 2006 Airborne SAR/Interferometric Radar Altimeter System (ASIRAS) campaign detected annual accumulation layers along the Expéditions Glaciologiques Internationales au Groenland (EGIG) traverse across central Greenland (Hawley et al., 2006; de la Pena et al., 2010). Previous accumulation estimates using ASIRAS layers along EGIG incorporate a maximum of two density profiles to calculate ASIRAS travel time (and thus determine ASIRAS layer depth) (Hawley et al., 2006; de la Pena et al., 2010). Concurrent to the 2006 radar campaign, Morris and Wingham (2011) conducted detailed measurements of near-surface density to $13 \mathrm{~m}$ depth using a neutron-probe (NP). Eight NP sites along a $250 \mathrm{~km}$ segment of the EGIG route provide ground-truthed density measurements for calculating ASIRAS travel time through the ice sheet's surface (Fig. 1). We present annual accumulation rates from 1959 to 2004 derived from NP density-adjusted ASIRAS layers (ASIRAS-NP accumulation record). We compare our ASIRAS-NP accumulation record to previous measurements of annual accumulation from shallow cores (Anklin and Stauffer, 1994; Fischer et al., 1995) and three RCMs. Detailed density, collected in conjunction with an airborne radar survey, offers the opportunity to understand radar-derived accumulation rates' sensitivity to density. We test the ASIRAS accumulation rate's sensitivity to density using simple Herron and Langway modeled density profiles in place of NP density measurements (ASIRAS-HL). Modeled density combined with radar layers may offer an alternative for deriving accumulation rates from radar layers lacking ground-truthed density.

\section{Background}

\subsection{EGIG line}

Major joint European expeditions across central Greenland were conducted in 1958-1959 (EGIG1) and 1967-1968 (EGIG2) (Renaud et al., 1963; Merlivat et al., 1973). Shallow cores drilled along the route led to the first isotopic climate curves produced by Dansgaard (2004). Merlivat et al. (1973) report a tritium based mean annual accumulation from 1959 to 1969 of $0.329 \mathrm{~m}$ water equivalent accumulation per year (mw.e. $\mathrm{a}^{-1}$ ) at site T31 (Station Centrale) and 0.243 (mw.e. $\mathrm{a}^{-1}$ ) at site T43 (Crête). Benson (1962) found mean annual accumulation from 1946 to 1955 of 0.355 $\left(\mathrm{m}\right.$ w.e. $\left.\mathrm{a}^{-1}\right)$ at $\mathrm{T} 31$.

A 1990-1992 reconstruction of the EGIG line by Technische Universität Braunschweig led to glacio-meteorological, isotopic/chemical, and snow accumulation studies (Anklin and Stauffer, 1994; Fischer et al., 1995). These studies found accumulation rates between 0.47 and $0.44 \mathrm{mw}$.e. $\mathrm{a}^{-1}$ at the western portion of EGIG, decreasing to 0.25 to 0.20 $\left(\mathrm{m}\right.$ w.e. $\mathrm{a}^{-1}$ ) along the eastern edge of the EGIG line. Fischer et al. (1995) report no long-term temporal changes in accumulation rates from 1955 to 1995.

Site T21 marks the approximate transition to the dry snow zone, with air temperatures upslope from T21 rarely exceeding $0^{\circ} \mathrm{C}$ (Fig. 1) (Morris and Wingham, 2011). Morris and Wingham (2011) observed a transition in surface conditions approximately $10 \mathrm{~km}$ uphill from site T31. Elevations upslope from T31 experience less persistent winds, leaving a smooth surface with undisturbed summer surface hoar (Morris and Wingham, 2011). Down-slope from T31 the upper snow layer appears to be wind-packed, with sastrugi marking the surface (Morris and Wingham, 2011).

\subsection{ASIRAS radar}

The European Space Agency originally designed ASIRAS to serve as a prototype for the CryoSat Mission (Stenseng et al., 2007). ASIRAS uses a Ku-band radar altimeter to measure ice sheet surface elevation and detect sub-surfaces layers. Stenseng et al. (2007) described the internal reflection horizons observed by ASIRAS as corresponding to density interfaces. ASIRAS radar has a carrier frequency of $13.5 \mathrm{GHz}$ and instrument bandwidth $B=1 \mathrm{GHz}$. The radar transect discussed in this paper was collected using low altitude mode (LAM). ASIRAS-LAM has $N_{\mathrm{s}}=4096$ echo samples, an uncompressed pulse length of $T_{\mathrm{uc}}=80 \mu \mathrm{s}$, an instrument sampling frequency of $F_{\mathrm{s}}=37.5 \mathrm{MHz}$, resulting in a range bin resolution of $\Delta R=0.109 \mathrm{~m}$, using the rangeresolution equation from (Cullen, 2010):

$\Delta R=\frac{T_{\mathrm{uc}} F_{\mathrm{s}} c}{2 B N_{\mathrm{s}}}$,

where $c$ is the speed of light, $\sim 299792458 \mathrm{~m} \mathrm{~s}^{-1}$.

Hawley et al. (2006) measured annual accumulation from 1995 to 2002 at site T21 using ASIRAS radar. The study used a single NP density profile, T21, to calculate radar travel time through snowpack and depth to the sub-surface layers. Hawley et al. (2006) establish ASIRAS internal reflection horizons as annual accumulation layers, correlating high density winter peaks with local peaks in radar power return. ASIRAS accumulation layers, examined down to $10 \mathrm{~m}$ depth, produced a mean annual accumulation of $0.47 \mathrm{mw}$.e. $\mathrm{a}^{-1}$ (similar to Anklin and Stauffer, 1994; Fischer et al., 1995). Hawley et al. (2006) found decreasing accumulation with increasing elevation and short-scale variability in line with Fischer et al. (1995) and Box et al. (2004). Hawley et al. (2006) observe upward curved reflectors in areas of steep slope and accumulation-driven layering, in agreement with Black and Budd (1964).

Helm et al. (2007) collected simultaneous ground-based density measurements and ASIRAS overflights in the perco- 


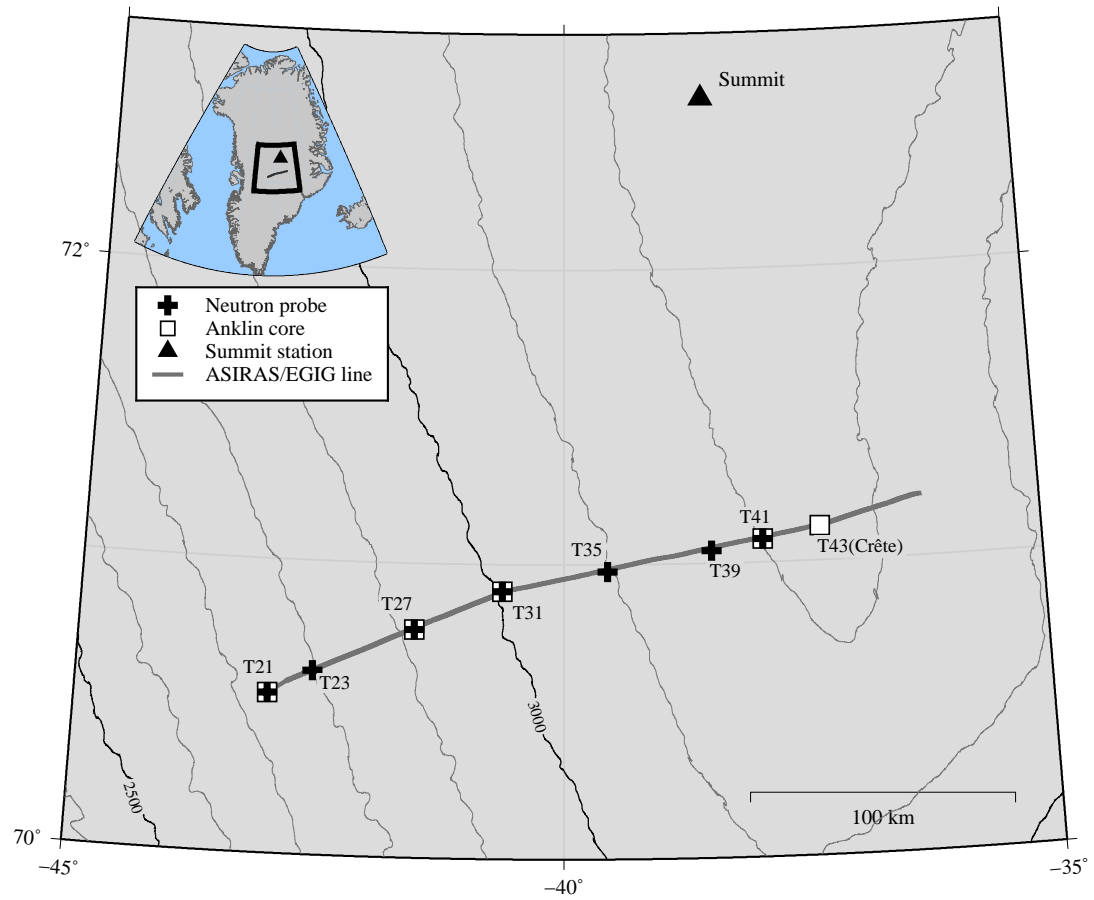

Figure 1. Field locations along a portion of the Expédition Glaciologique Internationale au Groenland (EGIG) traverse. The $250 \mathrm{~km}$ segment of ASIRAS radar data discussed in this paper spans 2700 to $3200 \mathrm{~m}$ elevation. Black crosses + show neutron-probe density T-sites from Morris and Wingham (2011). White squares $\square$ show Anklin and Stauffer (1994) shallow cores. The filled triangle $\boldsymbol{\Delta}$ shows the location of Summit Station for reference. $100 \mathrm{~m}$ contour intervals are displayed. Scale bar accurate at $71^{\circ} \mathrm{N}$ latitude.

lation zone along EGIG (downslope from this study). The dominant second peak observed in the ASIRAS waveform results from a heterogeneous zone of metamorphosed snow and ice lenses below the winter snowpack (Helm et al., 2007). From this finding, Helm et al. (2007) demonstrate ASIRAS's ability to derive winter accumulation rates. Similar to Black and Budd (1964); Hawley et al. (2006), Helm et al. (2007) found a strong correlation between surface gradient and accumulation rate, with higher accumulation rate in the plateau areas and lower accumulation rate on slopes.

de la Pena et al. (2010) presented mean accumulation rates for the period 1998-2003, calculated from six ASIRAS layers along $200 \mathrm{~km}$ of the EGIG route. de la Pena et al. (2010) used published T21 NP density values from Hawley et al. (2006) and a Summit density profile (located $150 \mathrm{~km}$ north of the EGIG line) to linearly interpolate density values, calculate radar travel time through snow/firn layers, calculate layer depth and accumulation rates along the EGIG line. de la Pena et al. (2010) report an average accumulation of $0.36 \mathrm{mw}$.e. $\mathrm{a}^{-1}$ with high spatial and temporal variability, and a decreasing accumulation gradient from west to east along EGIG consistent with previous studies of Anklin and Stauffer (1994), Fischer et al. (1995), Burgess et al. (2010), and the interannual variability observed by Fischer et al. (1995). de la Pena et al. (2010) presented a 15-20\% increase in accumulation above $3000 \mathrm{~m}$ over the past 20 25 years compared to Anklin and Stauffer (1994).

Simonsen et al. (2013) use ASIRAS layers down to approximately $15 \mathrm{~m}$ depth along EGIG to assess firn compaction. They use an automatic method to identify ASIRAS layers and confirm the layers represent isochrones spaced 1 year apart (Simonsen et al., 2013). Accumulation rates are not reported, as the study focused on firn compaction.

\subsection{EGIG-Ground in situ measurements}

\subsubsection{Shallow core accumulation}

Anklin and Stauffer (1994) drilled 11 shallow firn cores (referred to as T-sites, Fig. 1), 8 to $10 \mathrm{~m}$ depth, spaced $50 \mathrm{~km}$ apart along the EGIG line. Using hydrogen peroxide $\left(\mathrm{H}_{2} \mathrm{O}_{2}\right)$ analysis and snow density to identify the seasonal signal, Anklin and Stauffer (1994) report annual accumulation from 1969 to 1989 for T-sites along the EGIG line. Their accumulation rates fit with the general understanding of water vapor transport and snow accumulation across the Greenland Ice Sheet: higher accumulations near the coast $\left(0.44 \mathrm{~m}\right.$ w.e. $\left.\mathrm{a}^{-1}\right)$ gradually decreasing with increasing elevation $\left(0.25 \mathrm{~m}\right.$ w.e. $\mathrm{a}^{-1}$ at the east end of EGIG). Anklin and Stauffer (1994) found large variations of local annual accumulation rates from 1979 to 1989 , with typical standard deviations of 10 to $25 \%$. Changes in annual accumulation cor- 
related from site to site. Temporally, annual accumulation increased slightly in central Greenland and decreased slightly at middle and low elevations.

Fischer et al. (1995) drilled 18 shallow firn cores along the EGIG line during field campaigns in 1990 and 1992. Annual accumulation rates from 1984 to 1989 were determined by counting seasonally varying tracers $\delta^{18} \mathrm{O}$ and major ions. Measurements were collected at approximately eight samples per year. The 1990 campaign used seasonally varying hydrogen peroxide $\left(\mathrm{H}_{2} \mathrm{O}_{2}\right)$ analysis (in collaboration with Anklin and Stauffer, 1994) to determine summer maxima of flourimetric profiles. Fischer et al. (1995) observed distinct winter/summer pairings in the upper snow. Fischer et al. (1995) found layer thickness and accumulations similar to Anklin and Stauffer (1994) (0.47-0.43 m w.e. $\left.\mathrm{a}^{-1}\right)$, along the western portion of EGIG, decreasing to the east ( 0.25 to $0.20 \mathrm{~m}$ w.e. $\mathrm{a}^{-1}$, though fewer measurements exist to support the eastern accumulation rates). Fischer et al. (1995) argue for accumulation variations along EGIG due to large scale topographic valleys and ridges. The short timespan of the study, 1984 to 1989 , limited the identifiable temporal trend (Fischer et al., 1995).

\subsubsection{Neutron-probe densities and accumulation}

Morris and Wingham (2011) collected near-surface in situ neutron-probe (NP) density measurements along a $365 \mathrm{~km}$ section of the EGIG line in the spring and autumn of 2004 and spring and summer of 2006 (Morris and Wingham, 2014). The 2006 traverse coincided with airborne observations of sub-surface layers using ASIRAS. The probe used by Morris and Wingham (2011) consists of an annular radioactive americium-241/beryllium source of fast neutrons around a cylindrical detector of slow (thermal) neutrons (Morris and Cooper, 2003). The fast neutrons lose energy by scattering as they move through the snow. The count rate of slow neutrons arriving back at the detector per unit time relates to the density of the snow (Morris and Wingham, 2011). Morris (2008) derived theoretical calibration equations for count rate and snow density. See Morris and Wingham (2011), Morris and Wingham (2014) for descriptions of NP data collection.

Morris and Wingham (2011) collected 17 "T-site" NP density profiles and accumulation rates spanning ice-sheet elevations of 1940 to $3201 \mathrm{~m}$, (eight NP T-sites of this study are mapped on Fig. 1). The NP measured snow density from the surface down to approximately $13 \mathrm{~m}$ depth at the T-sites along the EGIG traverse. Morris and Wingham (2011) snowpit data show that very thin ice layers can occur at all sites but are not resolved by the NP measurements. Morris and Wingham (2011) observe "that the density peaks lie in winter snow but are formed during the following summer, when warmer temperatures promote densification in the near-surface layer (e.g., Zwally and Li, 2002)" (Morris and Wingham, 2011).

Zwally and Li (2002) describe two primary phases of the seasonal density cycle in the dry-snow region: temper- ature driven densification and accumulation rate driven compaction. Densification increases late spring to early summer as temperatures warm, with rates decreasing after a period of maximum firn compaction ends in late summer. The snow accumulation rate then dominates compaction through winter. This transition in near-surface snow from late-summer to autumn marks the annual seasonal change detected by ASIRAS (Hawley et al., 2006; de la Pena et al., 2010). The snow thickness between density peaks, adjusted to mean waterequivalent using density measurements, defines the NP estimate of annual accumulation (Hawley et al., 2008; Morris and Wingham, 2011).

\section{Methods}

\subsection{ASIRAS-traced layers}

We focus on a $250 \mathrm{~km}$ segment of the EGIG line spanning eight NP T-sites (Fig. 1). We trace 48 layers down to $20 \mathrm{~m}$ depth from a 29 April 2006 ASIRAS flight radargram (Fig. 2). Our radar profile starts at T21a (0 km distance) $2700 \mathrm{~m}$ elevation and ends $250 \mathrm{~km}$ to the east beyond the ice divide (3200 m elevation). Using SAR processed level_1b ASIRAS data, we apply the following signal processing techniques: waveform alignment, stacking, and gain. Each column of the radargram represents the centered mean of the surrounding 100 columns (hence 100 columns "stacked" into one record, representing approximately three horizontal meters). The ASIRAS signal weakens with increasing depth through the snowpack; thus we apply a ramped gain to the signal to enhance the visual contrast of the radargram. The ramped gain resembles an exponential gain, resulting in a $3 \times$ enhancement of layer intensity at $15 \mathrm{~m}$ depth and an $8 \times$ enhancement at $20 \mathrm{~m}$ depth.

We trace layers by tracking the maximum reflected power. The trace progresses by searching the adjacent column for a maximum power reflected within the vertical range of a moving window. Automated layer tracing occurs one layer at a time with visual inspection and user approval of the final traced layer. The shallowest (1st) layer represents the 2005 accumulation surface and the deepest (48th) traced layer represents the 1959 accumulation year (October 1958 to September 1959) (Fig. A1). Layers fade in intensity around $16 \mathrm{~m}$ depth along the western section of EGIG $(0-75 \mathrm{~km})$ and at $14 \mathrm{~m}$ depth along the rest of the line $(75-250 \mathrm{~km})$. The exact depth depends on the ASIRAS electromagnetic wave speed $v\left(\mathrm{~m} \mathrm{~s}^{-1}\right)$ through the snowpack. Electromagnetic wave speed $v$ relates to the real part of the dielectric permittivity $\epsilon_{\mathrm{r}}$ (dimensionless) which in the near-surface can be related to density $\rho\left(\mathrm{kg} \mathrm{m}^{-3}\right)$ by (Kovacs et al., 1995):

$\begin{aligned} v & =\frac{c}{\sqrt{\epsilon_{\mathrm{r}}}} \\ \epsilon_{\mathrm{r}} & =\left(1+8.45 \times 10^{-4} \rho\right)^{2},\end{aligned}$ 


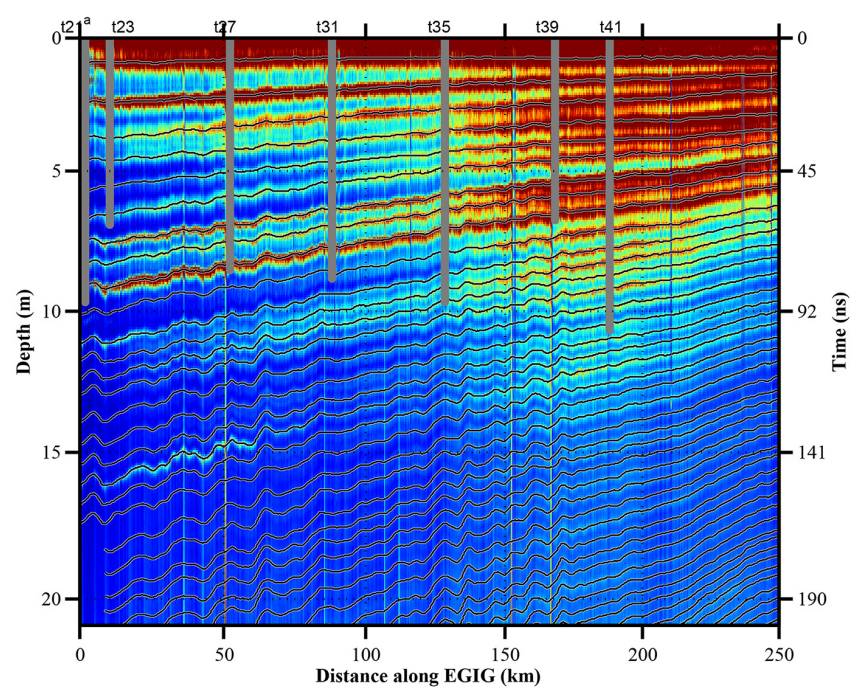

Figure 2. ASIRAS radargram of a portion of the 47 traced internal reflection horizons, or layers, down to $20 \mathrm{~m}$ depth. The uppermost layer represents the 2005 accumulation year. Distance along EGIG corresponds with gray line in Fig. 1, with $0 \mathrm{~km}$ starting at $2700 \mathrm{~m}$ on the western slope and $250 \mathrm{~km}$ ending below $3200 \mathrm{~m}$ on the eastern slope of the Greenland Ice Sheet. The left axis shows depth for NP and layers. The right axis shows two-way travel time of an ASIRAS radar pulse. See Appendix Fig. A1 for full extent of layers across EGIG.

where $c$ is the speed of light in a vacuum $\left(\sim 299792458 \mathrm{~m} \mathrm{~s}^{-1}\right)$.

Signal travel time will change based on the density of the snowpack. Dense coastal snowpack slows the signal speed compared to a less dense interior snowpack. Near the coast 45 nanoseconds (ns) of travel time equals $5.10 \mathrm{~m}$ depth, while the same travel time in the interior would equal $5.15 \mathrm{~m}$ depth. ASIRAS corrected with a coastal density profile gives a depth of $20.03 \mathrm{~m}$ at $190 \mathrm{~ns}$. The same $190 \mathrm{~ns}$ travel time reaches $20.24 \mathrm{~m}$ depth using the interior NP profile. The near-surface difference in travel time being unresolvable given ASIRAS's $0.109 \mathrm{~m}$ range-bin resolution (Sect. 2.2).

ASIRAS-NP and ASIRAS-HL accumulation rates have the same radar-time layer positions. The records differ only in the snow density used to adjust the radar signal propagation, which determines the depth, and therefore thickness of an annual accumulation layer. ASIRAS-NP, discussed in Sect. 3.3.1, interpolates densities between eight NP density profiles (Sect. 3.2) to calculate layer depths. ASIRAS-HL, discussed in Sect. 3.2.2, uses ASIRAS layers with HL density profiles to calculate layer depths.

\subsection{Density profiles}

\subsubsection{Neutron-probe density}

Detailed density profiles allow for more accurate calculations of ASIRAS radar travel time through the snowpack. Previ-

ous studies along EGIG (de la Pena et al., 2010; Hawley et al., 2006) rely on a maximum of two density profiles to constrain radar travel time for determination of layer depth. We expand the range of ground-truthed NP density measurements by combining 16 previously published (Morris and Wingham, 2011) density profiles from eight T-sites (T21a, T23, T27, T31, T35, T39, T41) in the dry-snow zone above $2700 \mathrm{~m}$ (Fig. 2). The deepest NP measurements are $11 \mathrm{~m}$, while our deepest ASIRAS layer reaches $30 \mathrm{~m}$ depth. We calculate densities below $11 \mathrm{~m}$ using the centimeter resolution density GISP2 B-core (NSIDC, 1997) at Summit. The easternmost NP density measurement (T41) at $10 \mathrm{~m}$ depth $\left(0.538 \mathrm{~g} \mathrm{~m}^{-3}\right)$ is similar to the GISP2 B-core density value at $10 \mathrm{~m}$ core depth $\left(0.529 \mathrm{~g} \mathrm{~m}^{-3}\right)$. The western edge of EGIG, at $2700 \mathrm{~m}$ elevation, has a $10 \mathrm{~m}$ density of $0.559 \mathrm{~g} \mathrm{~m}^{-3}$. We assume similar rates of densification below $10 \mathrm{~m}$ depth at $\mathrm{T} 21 \mathrm{a}$, T41, and GISP2. We append the GISP2 profile at $10 \mathrm{~m}$ depth to start where T21a NP density profile ends.

\subsubsection{Herron and Langway model density}

Logistical challenges for both ice coring and NP logging limit spatially detailed density measurements. Herron and Langway (1980)'s simple empirical model of polar snow densification provides an alternative for estimating ice sheet density in the absence of in situ measurements. The model allows us to generate a density profile at any point along EGIG with three input parameters: mean annual accumulation $A$, mean annual temperature $T$, and initial surface snow density $\rho_{0}$. The model has two stages of densification for depths above and below the "critical density" $\rho=0.55 \mathrm{Mg} \mathrm{m}^{-3}$. The "critical density" marks the transition from first-stage rapid densification due to grain settling and packing to second-stage slowed densification with depth (Herron and Langway, 1980). The model equations used for density $\rho$ at depth $h$ for the two stages of densification:

$$
\begin{array}{ll}
\text { Pre-critical: } & \text { Post-critical: } \\
\rho_{h}=\frac{\rho_{\mathrm{i}} \zeta_{0}}{1+\zeta_{0}} & \rho_{h}=\frac{\rho_{\mathrm{i}} \zeta_{1}}{1+\zeta_{1}} \\
\zeta_{0}=\exp \left[\rho_{\mathrm{i}} k_{0} h\right. & \zeta_{1}=\exp \left[\rho_{\mathrm{i}} k_{1} \frac{\left(h-h_{0.55}\right)}{A^{0.5}}\right. \\
\left.+\ln \left(\frac{\rho_{0}}{\rho_{\mathrm{i}}-\rho_{0}}\right)\right] & \left.+\ln \left(\frac{0.55}{\rho_{\mathrm{i}}-0.55}\right)\right] \\
k_{0}=11 \cdot \exp \left(\frac{-10160}{R \cdot T}\right) & k_{1}=575 \cdot \exp \left(\frac{-21400}{R \cdot T}\right),
\end{array}
$$

where $\quad h_{0.55}=\frac{1}{\rho_{\mathrm{i}} k_{0}}\left[\ln \frac{0.55}{\rho_{\mathrm{i}}-0.55}-\frac{\rho_{0}}{\rho_{\mathrm{i}}-\rho_{0}}\right], \quad k_{0} \quad$ and $\quad k_{1}$ are Arrhenius-type rate constants, and gas constant $R=8.314 \mathrm{~J} \mathrm{~K}^{-1} \mathrm{~mol}^{-1}, T=$ temperature in Kelvin and the density of ice $\rho_{\mathrm{i}}=0.917 \mathrm{Mgm}^{-3}$.

We calculate densities along EGIG using mean annual accumulation from Burgess et al. (2010), temperatures calculated using latitude and elevation dependent lapse rates from 
Steffen and Box (2001), and Morris and Wingham (2011)'s T-site surface densities as inputs to Herron and Langway (1980)'s model. We use densities generated from Herron and Langway (1980)'s model to adjust radar travel time and derive the ASIRAS-HL accumulation rate as a comparison to the NP-derived ASIRAS-NP accumulation rates.

\subsection{Accumulation rates from ASIRAS}

\subsubsection{ASIRAS-NP: accumulation rate using neutron-probe densities}

The 16 NP density profiles at eight T-sites (T21a, T23, T27, T31, T35, T39, T41) bound by the combined T21a and GISP2 b-core densities on the west and the T41 and GISP2 b-core on the east, provide the anchor points for interpolating depth-density values at every point along the EGIG line. We calculate annual accumulation rates from 1959 to 2004 at the T-sites (Table A1). We refrain from calculating a 2005 annual accumulation due to its proximity to the April 2006 ice sheet surface at time of radar and NP collection. The NP densities represent the most detailed density measurements along EGIG, correcting ASIRAS travel time through the snowpack to create the ASIRAS-NP accumulation rates.

\subsubsection{ASIRAS-HL: accumulation rate using Herron and Langway densities}

Taking detailed NP density measurements remains beyond the scope of most radar surveys. We explore using simple Herron and Langway (1980) model densities (HL) to produce accumulation rates from ASIRAS radar layers (ASIRAS$\mathrm{HL})$. We examine the accumulation rate difference when using modeled density data (ASIRAS-HL) and using NP density (ASIRAS-NP). Using spatially continuous input parameters of accumulation, temperature, and surface density, we generate HL density profiles for each radar trace (one approximately every $3 \mathrm{~m}$ horizontally, Sect. 3.1) along the $250 \mathrm{~km}$ segment of EGIG.

We examine accumulation rate sensitivity to density by reducing the number of HL density profiles used to correct layer depth along the $250 \mathrm{~km}$ EGIG segment. Distance intervals and their corresponding number of density profiles per the $250 \mathrm{~km}$ EGIG segment are the following: $250 \mathrm{~km}$ (HL250, 1 profile), $125 \mathrm{~km}$ (HL125, 2 profiles), $50 \mathrm{~km}$ (HL50, 5 profiles), $30 \mathrm{~km}$ (HL30, 8 profiles), and $15 \mathrm{~km}$ (HL15, 17 profiles). We linearly interpolate between the HL profiles to obtain a density profile at every point along EGIG.

\subsection{EGIG-Ground accumulation measurements}

We combine shallow firn core records from Anklin and Stauffer (1994) and NP based accumulation rates calculated by Morris and Wingham (2011) to establish EGIG-Ground records spanning 1978-2004 at T21, T27, T31, T41. Site
T43 has 12 annual accumulations from 1976 to 1988 but no NP measurements (Anklin and Stauffer, 1994). Anklin and Stauffer (1994) cores generally span 1978 to 1988 while the Morris and Wingham (2011) accumulation rates span the mid-1980s to 2004. We use the mean of the two records at site T41 where the studies overlap. Sites T21, T27, and T31 do not have overlapping records, with no accumulation rates for years 1989 and 1990 at T21 and T27 and 1989 for T31. These EGIG-Ground records serve as a basis for comparison of accumulation rates derived from ASIRAS layers (Fig. 3).

\subsection{ASIRAS-NP comparison to Regional Climate Models}

We validate ASIRAS-NP accumulation rates using EGIGGround point accumulation records (Anklin and Stauffer, 1994; Morris and Wingham, 2011), then compare our results to accumulation rates from three Regional Climate Models (RCMs): Modèle Atmosphérique Régional (MAR) (Tedesco et al., 2015), the polar version of the Regional Atmospheric Climate Model (RACMO2.3) (Noël et al., 2015), and the calibrated Fifth Generation Mesoscale Model modified for polar climates (Polar MM5) (Burgess et al., 2010).

As discussed in Sects. 2.3 and 3.1, ASIRAS waveform results from a heterogeneous zone of metamorphosed snow and thin ice lenses below the winter snowpack (Helm et al., 2007; Morris and Wingham, 2011). Therefore we define the ASIRAS-NP accumulation year as representing October to September. Comparisons between ASIRAS-NP and the RCMs occur by sampling ASIRAS-NP at the RCM grid points along the $250 \mathrm{~km}$ EGIG segment (Fig. 4). MAR annual snow accumulation spans 1958 to 2013 (Tedesco et al., 2015). Data obtained for this study defines the accumulation year as January to December. MAR has a $25 \mathrm{~km}$ spatial resolution, resulting in approximately 11 MAR accumulation estimates along the $250 \mathrm{~km}$ EGIG line.

RACMO2.3 estimates monthly cumulated total surface mass balance (SMB) (with SMB defined as precipitation minus sublimation, snow erosion, and runoff) for the period 1958-2013 (Noël et al., 2015). We sum RACMO2.3 monthly accumulation values from October to September to align annual accumulation with the ASIRAS-NP defined accumulation year of (Sect. 3.1). The RACMO2.3 spatial resolution of $11 \mathrm{~km}$ results in 24 modeled accumulations along EGIG.

Burgess et al. (2010) re-sample the Polar MM5's $24 \mathrm{~km}$ horizontal grid output to a $1.25 \mathrm{~km}$ equal-area grid using bilinear interpolation (Burgess et al., 2010; Rignot et al., 2008). Polar MM5's hydrologic year spans from 14 September to 15 September. The $24 \mathrm{~km}$ original spacing results in approximately 11 Polar MM5 data points along the $250 \mathrm{~km}$ EGIG line. The Burgess et al. (2010) $1.25 \mathrm{~km}$ grid down sampled to our $2 \mathrm{~km}$ grid results in 125 points along EGIG. Using generic mapping tools (GMTs) (Wessel et al., 2013) nearneighbor command with bilinear interpolation we interpolate from the $1.25 \mathrm{~km}$ grid to a $2 \mathrm{~km}$ grid spacing. 

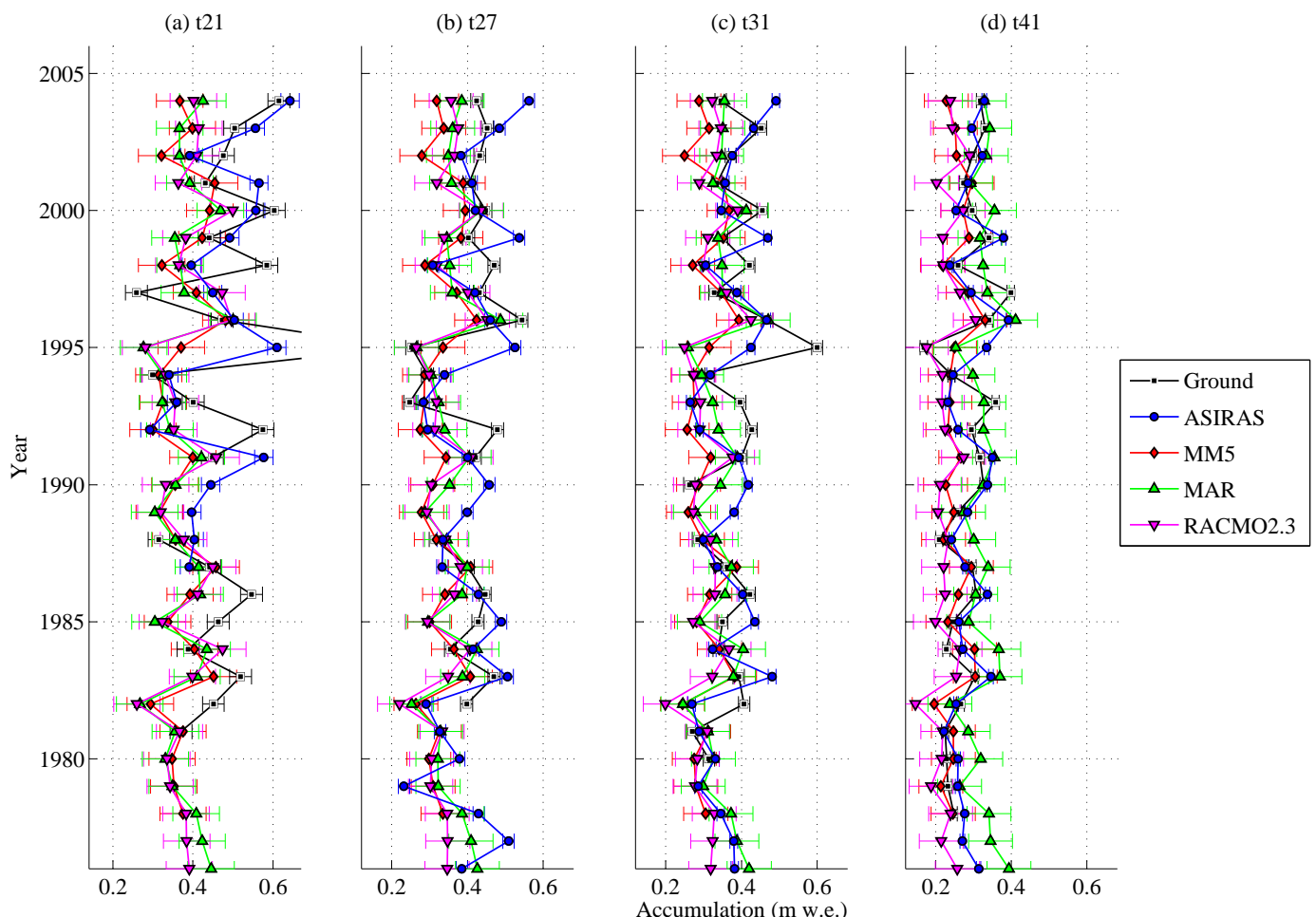

Figure 3. Mean annual accumulation rates at T21, T27, T31, and T41 from ASIRAS-NP, three Regional Climate Models (MM5, MAR, RACMO2.3), and combined EGIG-Ground measurements from Anklin and Stauffer (1994) and Morris and Wingham (2011). ASIRASNP and EGIG-Ground accumulation rates from 1985 to 2004 are not statistically different at the four sites. The RCMs underestimate accumulation compared to ASIRAS-NP, but succeed in tracking the general accumulation trend across the $250 \mathrm{~km}$ EGIG segment.

\section{Results}

\subsection{ASIRAS-NP accumulation rate}

The layers detected by ASIRAS with depths calculated using NP profiles, provide a spatially continuous record of accumulation across $250 \mathrm{~km}$ of the EGIG route. We trace layers to $30 \mathrm{~m}$ depth and report accumulation rates for 46 layers spanning 1959-2004 (Fig. A1). The mean accumulation rate for the entire $250 \mathrm{~km}$ EGIG segment is $0.337 \mathrm{mw}$.e. $\mathrm{a}^{-1}$ from 1959 to 2004. We focus our reported results on the period 1985 to 2004, during which EGIG-Ground measurements exist for comparison. Figure 2 displays spatial and temporal variations in layers across the EGIG segment.

Temporally, accumulation rates increase over time, with the onset of increase occurring in the mid1970s. From 1959 to 1964, mean accumulation was 0.277 mw.e. $\mathrm{a}^{-1}$. From 1965 to 1974 , mean accumulation was $0.270 \mathrm{mw}$.e. $\mathrm{a}^{-1}$. From 1975 to 1984 , mean accumulation was $0.327 \mathrm{~m}$ w.e. $\mathrm{a}^{-1}$. Mean ASIRAS-NP accumulation from 1985 to 1994 was $0.328 \mathrm{mw}$.e. $\mathrm{a}^{-1}$. Accumulation for the period 1995 to $2004\left(0.382 \mathrm{mw}^{2} . \mathrm{a}^{-1}\right)$ increases by $16 \%$ compared to the previous 10 -year period. Table 1 summarizes the 10-year mean accumulation results. See Table A1 for detailed accumulations from 1959 to 2004.
Table 1. Summary table of mean accumulation rates (meters water equivalent) 1959-2004.

\begin{tabular}{lcccc}
\hline Period & ASIRAS-NP & MM5 & MAR & RACMO \\
\hline $1959-2004$ & $0.337 \pm 0.03$ & $0.288 \pm 0.04$ & $0.329 \pm 0.03$ & $0.279 \pm 0.06$ \\
\hline $1995-2004$ & $0.382 \pm 0.03$ & $0.307 \pm 0.05$ & $0.347 \pm 0.02$ & $0.306 \pm 0.04$ \\
$1984-1995$ & $0.328 \pm 0.02$ & $0.279 \pm 0.04$ & $0.326 \pm 0.02$ & $0.279 \pm 0.06$ \\
$1975-1984$ & $0.327 \pm 0.01$ & $0.299 \pm 0.04$ & $0.345 \pm 0.03$ & $0.283 \pm 0.06$ \\
$1965-1974$ & $0.270 \pm 0.01$ & $0.272 \pm 0.04$ & $0.316 \pm 0.03$ & $0.257 \pm 0.06$ \\
$1959-1964$ & $0.277 \pm 0.01$ & $0.276 \pm 0.04$ & $0.300 \pm 0.02$ & $0.263 \pm 0.05$ \\
\hline
\end{tabular}

Spatially, accumulation decreases with increasing elevation and distance from the coast. Mean annual accumulation for 1985 to 2004 at T21a $(0 \mathrm{~km})$ is $0.455 \mathrm{mw}$.e. $\mathrm{a}^{-1}$, gradually decreasing to $0.378 \mathrm{mw}$ we. $\mathrm{a}^{-1}$ at T31, $0.297 \mathrm{mw}$.e. $\mathrm{a}^{-1}$ at T41, and $0.254 \mathrm{mw}$.e. $\mathrm{a}^{-1}$ at the $250 \mathrm{~km}$ mark (Table 2). Using the transition in surface conditions occurring near T31 to divide EGIG, we examine accumulation rate changes over time above and below T31. Below T31, mean accumulation increased by $20 \%$ over the 10-year period 1995 to 2004 ( $0.465 \mathrm{mw}$.e. $\left.\mathrm{a}^{-1}\right)$ compared to the 1985 to 1994 period $\left(0.387 \mathrm{mw}\right.$.e. $\left.\mathrm{a}^{-1}\right)$. Above T31 accumulation increased by $13 \%$ over the 10 -year period 1995 to $2004\left(0.335 \mathrm{ma}^{-1}\right)$ compared to the 1985 to 1994 period $\left(0.296 \mathrm{ma}^{-1}\right)$. 

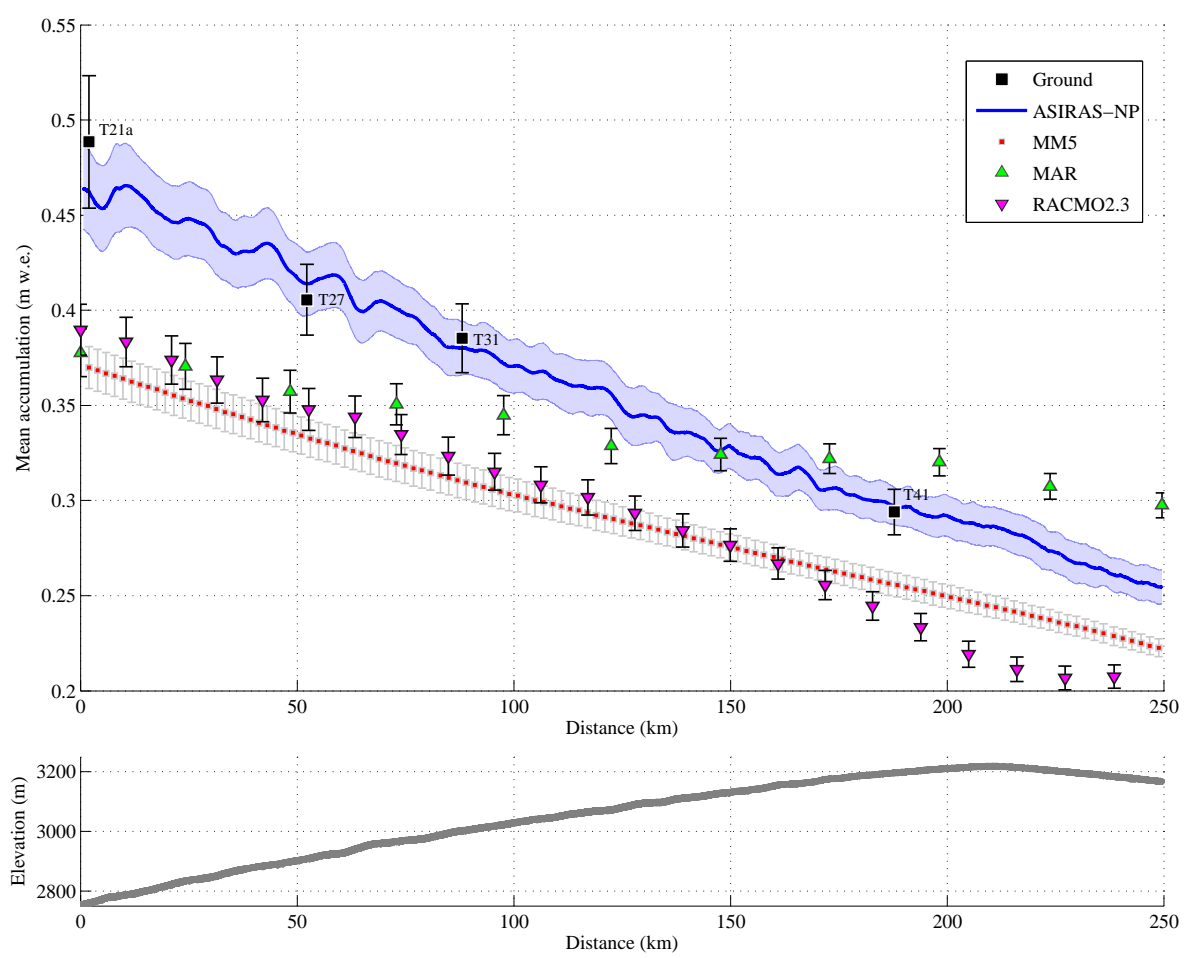

Figure 4. Mean water-equivalent accumulations rates from 1985 to 2004 along EGIG line. The solid blue line shows this study's ASIRAS-NP accumulation derived from ASIRAS layers and NP densities. Black squares depict mean accumulation from T-sites with NP/Core EGIGGround measurements from Anklin and Stauffer (1994) and Morris and Wingham (2011) spanning 1985-2004 (T21, T27, T31, T41). Snow accumulation from three Regional Climate Models, Polar MM5, MAR, and RACMO2.3 is plotted for comparison. The models generally underestimate accumulation compared to ASIRAS-NP and EGIG-Ground in situ estimates. Radar-derived accumulation rates are highest near the coast where density values have the largest range. Standard uncertainties displayed are for accumulation values from 1985 to 2004.

\subsection{ASIRAS-NP and RCMs vs. EGIG-Ground}

The published EGIG-Ground in situ accumulation records discussed in Sect. 3.4 serve as the "known" accumulation rate to which we compare our ASIRAS-NP record and the RCMs. We focus on four sites (T21, T27, T31, T41) that have accumulation records from both Anklin and Stauffer (1994) and Morris and Wingham (2011). Figure 3 presents these comparisons at the four T-sites. We compare the full records year by year using a nonparametric Wilcoxon sign-rank test designed for two populations with paired observations. The differences of the paired observations will have a distribution whose median is zero at the $5 \%$ significance level if the two populations are not statistically different. The zero median of the paired and differenced records indicate the ASIRAS-NP and EGIG-Ground accumulations come from identical populations. The paired yearly accumulations for RCMs and EGIG-Ground at the four T-sites are significantly different based on a Wilcoxon signed-rank test. In addition to the year-to-year comparisons, no statistical difference exists between EGIG-Ground and ASIRAS-NP mean accumulation from 1985 to 2004 at sites T21, T27, T31, T41 (Table 2). We conducted an analysis of variance test to compare means of the 20-year (1985-2004) annual snow accumulation for ASIRAS-NP and EGIG-Ground, and the RCMs and ASIRAS-NP accumulation for 1978 to 2004. Significance differences were determined for alpha $<0.05$. Pearson's correlation coefficients for ASIRAS-NP and EGIG-Ground and RCM accumulations for the entire record (1959-2004) range from 0.56 to 0.19 (Table A2).

\subsection{ASIRAS-NP vs. Regional Climate Models}

Regional Climate Models RACMO2.3, MAR, and Polar MM5, generally underestimate mean annual snow accumulation along EGIG compared to ASIRAS-NP (Fig. 4). ASIRAS-NP and the RCM accumulation rates from 1978 to 2004 positively correlate at T-sites T21, T23, T27, and T41 for MAR, MM5, and RACMO2.3 (Table A2). An ANOVA comparison of means for 1959 to 2004 shows RCM and ASIRAS-NP mean accumulations are statistically different at T-sites T21, T27, T31, and T41. Using a Wilcoxon signedrank test, year-to-year comparisons show significant statistical differences between all three RCMs and ASIRAS-NP at the T-sites. RCM mean accumulations along EGIG are significantly lower for the time period coincident with EGIGGround measurements, 1985 to 2004 (Fig. 4). We focus on 
Table 2. Summary table of mean accumulation rates (m w.e. $\left.a^{-1}\right), 1985-2004$, for Fig. 4.

\begin{tabular}{lcccc}
\hline Study & T21 & T27 & T31 & T41 \\
\hline EGIG-Ground & $0.488 \pm 0.03$ & $0.405 \pm 0.02$ & $0.385 \pm 0.02$ & $0.294 \pm 0.01$ \\
ASIRAS & $0.455 \pm 0.02$ & $0.409 \pm 0.02$ & $0.378 \pm 0.01$ & $0.297 \pm 0.01$ \\
MM5 & $0.370 \pm 0.01$ & $0.333 \pm 0.01$ & $0.311 \pm 0.06$ & $0.257 \pm 0.06$ \\
MAR & $0.373 \pm 0.02$ & $0.357 \pm 0.02$ & $0.344 \pm 0.01$ & $0.322 \pm 0.01$ \\
RACMO2.3 & $0.390 \pm 0.02$ & $0.348 \pm 0.02$ & $0.318 \pm 0.01$ & $0.233 \pm 0.01$ \\
\hline
\end{tabular}

Table 3. Mean percentage difference between ASIRAS-NP and RCMs for periods 1985-1994, 1995-2004, 1985-2004.

\begin{tabular}{lccc}
\hline Period & $\begin{array}{c}\text { RACMO } \\
\text { EGIG }\end{array}$ & MAR & MM5 \\
\hline $1985-2004$ & $18 \%$ & $3 \%$ & $17 \%$ \\
$1995-2004$ & $17 \%$ & $4 \%$ & $13 \%$ \\
$1985-1994$ & $13 \%$ & $-4 \%$ & $21 \%$ \\
\hline \multicolumn{4}{c}{ Below T31 } \\
\hline $1985-2004$ & $16 \%$ & $16 \%$ & $20 \%$ \\
$1995-2004$ & $17 \%$ & $17 \%$ & $16 \%$ \\
$1985-1994$ & $9 \%$ & $8 \%$ & $25 \%$ \\
\hline \multicolumn{4}{c}{ Above T31 } \\
\hline $1985-2004$ & $18 \%$ & $-4 \%$ & $15 \%$ \\
$1995-2004$ & $17 \%$ & $-3 \%$ & $12 \%$ \\
$1985-1994$ & $16 \%$ & $-10 \%$ & $19 \%$ \\
\hline
\end{tabular}

the period 1985 to 2004 to calculate standard uncertainty $\left(\frac{\sigma}{\sqrt{n}}\right.$, where $\sigma=$ standard deviation and $\left.n=20\right)$.

Mean RACMO accumulation $\left(0.297 \mathrm{mw} . e . \mathrm{a}^{-1}\right)$ from 1985 to 2004 across the entire $250 \mathrm{~km}$ EGIG segment is $18 \%$ lower than ASIRAS-NP $\left(0.356 \mathrm{mw}^{\text {we. }} \mathrm{a}^{-1}\right)$ (Table 3). Mean ASIRAS-NP and RACMO accumulations rates from 1985 to 2004 differ spatially along EGIG (Fig. 4). Using the transition in surface conditions occurring near T31 $(3000 \mathrm{~m}$ elevation) to divide EGIG, RACMO underestimates accumulation by $16 \%$ downslope from T31 compared to ASIRASNP. Above T31, mean RACMO accumulation is $18 \%$ lower than ASIRAS-NP. Accumulation rates change over time with differing rates above and below T31. RACMO underestimates accumulation down-slope of $\mathrm{T} 31$ by $17 \%$ compared to ASIRAS-NP from 1995 to 2004. Below T31 from 1985 to 1994 RACMO accumulation estimates are $9 \%$ lower than ASIRAS-NP. Above T31, RACMO underestimates accumulation by $16 \%$ for the $1985-1994$ period and $17 \%$ for $1995-$ 2004, relative to ASIRAS-NP.

Mean MAR accumulation $\left(0.336 \mathrm{mw}\right.$.e. $\left.\mathrm{a}^{-1}\right)$ from 1985 to 2004 across the entire $250 \mathrm{~km}$ EGIG segment is $3 \%$ lower than ASIRAS-NP $\left(0.355\right.$ mw.e. $\left.\mathrm{a}^{-1}\right)$. Spatially, MAR both underestimates and overestimates accumulation along EGIG. MAR underestimates accumulation by $16 \%$ downslope from
T31 compared to ASIRAS-NP. Above T31, mean MAR accumulation rates are $4 \%$ higher than ASIRAS-NP. Accumulation rates vary over time with differing rates above and below T31. MAR accumulations from 1995 to 2005 are $17 \%$ lower than ASIRAS-NP accumulations down-slope of T31. Below T31 from 1985 to 1994 MAR accumulations are $8 \%$ lower than ASIRAS-NP. East of T31, MAR accumulation is $10 \%$ higher for 1985-1994 and 3\% higher for 1995-2004, relative to ASIRAS-NP (Table 3).

Mean Polar MM5 accumulation $\left(0.293 \mathrm{mw}^{\mathrm{m} . \mathrm{a}^{-1}}\right)$ from 1985 to 2004 across the entire $250 \mathrm{~km}$ EGIG segment is $17 \%$ lower than ASIRAS-NP $\left(0.356 \mathrm{~m}_{\text {w.e. }} \mathrm{a}^{-1}\right)$. Mean ASIRASNP and Polar MM5 accumulations rates from 1985 to 2004 differ spatially along EGIG. Using the transition in surface conditions occurring near T31 (3000 m elevation) to divide EGIG, Polar MM5 underestimates accumulation by $20 \%$ downslope from T31 compared to ASIRAS-NP. Above T31, mean Polar MM5 accumulation is $15 \%$ lower than ASIRASNP. Accumulation rates change over time with differing rates above and below T31. Polar MM5 underestimates accumulation down-slope of T31 by $16 \%$ compared to ASIRAS-NP from 1995 to 2004. Below T31 from 1985 to 1994 Polar MM5 accumulation estimates are $25 \%$ lower than ASIRASNP. Above T31, Polar MM5 underestimates accumulation by $12 \%$ for the 1985-1994 period and $19 \%$ for $1995-2004$, relative to ASIRAS-NP.

\subsection{ASIRAS-NP vS. ASIRAS-HL: accumulation rate sensitivity to density}

Mean percentage accumulation differences between ASIRAS-NP and ASIRAS-HL decrease with increasing age/depth of the layers (Fig. 5). Figure 5 plots the mean difference between ASIRAS-NP and ASIRAS-HL for the upper five layers (2000-2004), period (1985-1989), and the 20-year period 1985-2004 layers. On average the deeper the layer, the lower the difference between ASIRAS-NP and ASIRAS-HL accumulation rates. The upper five layers differ by $4 \%$ on average. The 1985-1989 period differs by $3.2 \%$. Overall, for the period 1985-2004, mean ASIRAS-HL accumulation is $4.5 \%$ lower than ASIRAS-NP accumulation.

We test sensitivity to density by limiting the number of HL density profiles along EGIG and interpolating density values 


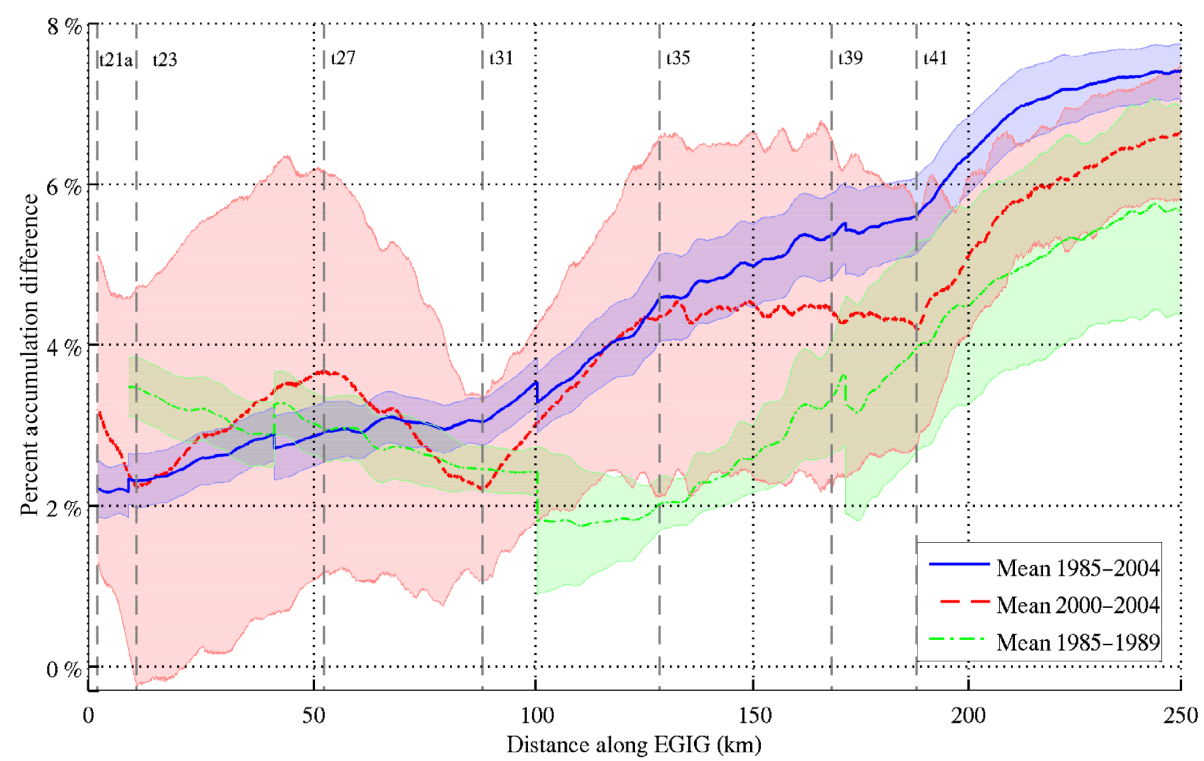

Figure 5. Mean percentage accumulation difference between ASIRAS-NP and ASIRAS-HL for the upper five (2000-2004), lower five (1985-1989), and 1985-2004 layers. In general, differences in accumulation decrease with increasing depth/age of the layers. ASIRAS-HL accumulation differs from ASIRAS-NP accumulation by $4.5 \%$ for the $1985-2004$ period. The low mean differences across the $250 \mathrm{~km}$ EGIG segment indicate that modeled densities provide accurate accumulation estimates in radar survey regions lacking in situ density measurements.

between the profiles. Using one density profile (HL250 km) for the entire $250 \mathrm{~km}$ EGIG segment results in a $10 \%$ difference in ASIRAS-NP and ASIRAS-HL. Incorporating two density profiles (HL125 km) halves the accumulation difference from 10 to $5 \%$. The ASIRAS-NP and ASIRAS-HL accumulation difference reduces to $3 \%$ for $\mathrm{HL} 50 \mathrm{~km}$ (5 profiles), HL30 km (8 profiles), and HL15 km (17 profiles).

\section{Discussion}

\subsection{ASIRAS-NP accumulation rate}

The ASIRAS layers combined with NP density data improve understanding of accumulation between T-sites, showing detailed peaks and valleys in accumulation as seen and attributed to topography by Arcone et al. (2005), Hawley et al. (2006), Black and Budd (1964), Miége and et. al. (2013). The undulating layers observed in Fig. 2 reinforce ice core observations of high spatial variability (Spikes et al., 2004). Spatial variability decreases with increasing depth, as layers undergo compaction. The fluctuations of layer depth and vertically aligned dips and peaks may indicate surface accumulation anomalies (Arcone et al., 2005). A gradual horizontal migration of undulations over time could produce spatially periodic accumulation rates, as described by Arcone et al. (2005). Undulations preserved from year to year are visible east of T27 at $60 \mathrm{~km}$ and from 125 to $175 \mathrm{~km}$ along the EGIG line (Fig. 2 and Fig. A1). The oscillations are visible along the $250 \mathrm{~km}$ EGIG segment in the long term mean temporal ac- cumulation rate in Fig. 4. Visual inspection of layer thickness for a given year (Figs. 2 and A1) allows us to argue for high confidence in the extreme values measured by ASIRAS-NP.

In comparison to historical records, de la Pena et al. (2010) and Hawley et al. (2014) observed accumulation increases of 19 and $10 \%$ over the last 30 and 52 years, respectively, in high-elevation interior Greenland. We report a $16 \%$ increase in accumulation for the period 1995-2004 compared to 1985-1994 and a $41 \%$ increase in accumulation for the period 1965-1974 (Table 1). We observe an east-west gradient along EGIG of increasing accumulation, with lower accumulation increases in the east and higher increases to the west. The east-west gradient strengthens from 1995 to 2004, when ASIRAS-NP is $20 \%$ higher than ASIRAS-HL below $\mathrm{T} 31$ and $13 \%$ higher above T31.

\subsection{ASIRAS-NP vs. EGIG-Ground}

The patterns observed by Anklin and Stauffer (1994), Fischer et al. (1995), Morris and Wingham (2011) at the T-sites align with the overall trend observed by de la Pena et al. (2010) along EGIG of decreasing accumulation from the coast to the interior. The year-to-year comparisons from Fig. 3 using Paired Wilcoxon signed-rank span every year with observations for both ASIRAS-NP and EGIG-Ground. Year-toyear comparisons show that ASIRAS-NP tracks the EGIGGround measurements consistently. EGIG-Ground accumulation minima and maxima are not always consistent across the EGIG route for a given year (e.g., the T31 record's maxima occurs in 1995, while T27 and T41 records have near 
minimum values for 1995). We attribute site to site accumulation fluctuation in the EGIG-Ground record to the limited spatially extent of a given shallow core or snowpit. Accumulation extremes seen in the ASIRAS-NP record are consistent across the T-sites (low in 1998, high in 1996).

\subsection{ASIRAS-NP vs. Regional Climate Models}

Polar MM5 underestimates accumulation relative to ASIRAS-NP and EGIG-Ground (Fig. 4). Mean Polar MM5 accumulation from 1985 to 2004 along EGIG is $0.06 \mathrm{~m}$ (17\%) lower than ASIRAS-NP measurements. The mean $0.06 \mathrm{~m}$ difference falls within Polar MM5's standard deviation of accumulation along EGIG (0.025-0.075) (Burgess et al., 2010). Polar MM5's consistent underestimate of accumulation relative to ASIRAS-NP and EGIG-Ground may be explained by the measurements used to tune Polar MM5. Burgess et al. (2010) added spatial and temporal resolution to Greenland ice sheet accumulation by calibrating the Polar MM5 using firn cores and meteorological stations data. Burgess et al. (2010) re-sample the Polar MM5's 24 km horizontal grid output to a $1.25 \mathrm{~km}$ equal-area grid using bilinear interpolation (Burgess et al., 2010; Rignot et al., 2008). The $24 \mathrm{~km}$ original spacing results in approximately eight Polar MM5 data points along the $250 \mathrm{~km}$ EGIG line. These eight Polar MM5 points were tuned from a network of cores and automatic weather stations and thus were not forced to correspond exactly with cores along EGIG. Burgess et al. (2010) omit the majority of the T-site accumulation rates along EGIG, including only sites T31, T41, and T43. ASIRAS-NP provides detailed accumulation measurements every $3 \mathrm{~m}$, nearly continuous tracking along EGIG relative to Polar MM5. The increased spatial resolution may contribute to the difference in accumulation rates.

Yearly comparisons of the entire record of ASIRAS-NP and Polar MM5 snow accumulations (Fig. 3) show positive correlations for T21a, T23, T27, T41, T43 (Table A2). Correlations between ASIRAS-NP and Polar MM5 demonstrate the model's utility for predicting the relative year-to-year accumulation trend. ASIRAS-NP and Polar MM5 both track the general coast to interior accumulation gradient as elevation increases (Fig. 4). Morris and Wingham (2011) describe a noticeable change in surface conditions near site T31. Above T31, summer surface hoar appears undisturbed, possibly from less persistent winds. Down-slope from T31 katabatic winds pack the upper snow layer and form sastrugi, which may influence spatial variability and preservation of accumulation layers. Signal preserved in the upper ASIRASNP accumulation layers would be absent in the Polar MM5 record, possibly explaining Polar MM5's 25\% accumulation underestimate compared to ASIRAS-NP below T31. Elevations upslope from T31 experience less persistent winds, leaving a smooth surface with undisturbed summer surface hoar, with a mean Polar MM5 accumulation $18 \%$ lower than ASIRAS-NP. The spatial gradient has a noticeable temporal component when comparing ASIRAS-NP and Polar MM5. From 1985 to 1994, Polar MM5 accumulation is $28 \%$ lower below T31 and $21 \%$ lower above T31 compared to ASIRASNP. The east-west gradient along EGIG strengthens from 1995 to 2004, when Polar MM5 is $23 \%$ lower than ASIRASNP below T31 and 16\% lower above T31. Polar MM5's recent accumulation rates near EGIG rely on firn cores drilled prior to 1995 and limited automatic weather stations at high elevation. Thus recent observed increases in accumulation at high elevation due to increased moisture availability from warming (de la Pena et al., 2010; Hawley et al., 2014) may not appear in the Polar MM5 record.

\subsection{ASIRAS-NP vs. ASIRAS-HL: accumulation rate sensitivity to density}

Subtracting the ASIRAS-HL and ASIRAS-NP accumulation rates tests the radar-derived accumulation rate's sensitivity to density. The ASIRAS layers' position in radar time remains constant between the ASIRAS-NP and ASIRAS-HL. Density, which determines radar velocity and therefore waterequivalent depth, is the lone variable between ASIRAS-NP and ASIRAS-HL accumulation records. The largest differences in accumulation occur where NP and HL densities differ most. NP density profiles provide detailed vertical resolution of seasonal density fluctuation. Seasonal density fluctuations are most prominent in the near surface layers and in areas with large variability in temperature and accumulation (e.g., coastal, lower elevations). Though the simple three parameter Herron and Langway (1980) model cannot capture the detailed seasonal density variations, the model's generalized density in the near-surface generates ASIRAS-HL accumulation rates within $4.5 \%$ of ASIRAS-NP. NP and HL densities resemble each other most at deeper depths as compaction smooths seasonal fluctuations in density. Thus the deeper layers have the smallest mean percentage accumulation difference (3\%) (Fig. 5). The low (4.5\%) mean accumulation differences along EGIG indicate that modeled density values provide reasonable accumulation estimates in areas with low variability in density and where detailed density profiles are unavailable. Below $11 \mathrm{~m}$ depth, differences are related to Summit GISP2b-Shifted and Summit GISP2b shallow density core bounding the west $(0 \mathrm{~km})$ and east $(250 \mathrm{~km})$ margins, respectively, of the EGIG line. No dominant spatial pattern of accumulation differences emerges from west to east. The mean of the lower five accumulation years (1985-1989) account for the smallest accumulation differences from 60 to $250 \mathrm{~km}$. The largest differences along EGIG occur on the east end $(225-250 \mathrm{~km})$ where ASIRAS-NP is constrained by a Summit density core. Abrupt jumps in mean percent accumulation difference occur where the number of layers is included in the average change.

Recall the spatially continuous nature of the density inputs for the ASIRAS-HL accumulation record (HL density profiles spaced $3 \mathrm{~m}$ apart). These density inputs were driven 
by highly resolved HL model inputs of accumulation, temperature and surface density. ASIRAS-HL accumulation accuracy relative to ASIRAS-NP may be due to these model inputs. We test this possibility with the HL250 km, HL125 km, etc., accumulation records, which rely on a limited number of density profiles and interpolation. The moderate reduction from 10 to $5 \%$ accumulation difference for HL250 km and HL125 km is likely due to the linear gradients (increasing accumulation downslope, decreasing elevation, increasing temperature) of the HL model input parameters along the $250 \mathrm{~km}$ EGIG segment. The two density profiles of HL125 km cover both the lower and upper range of the gradients. The interpolation between these two contain the majority of density variation seen in the ASIRAS-NP, thus accounting for the $4 \%$ mean accumulation difference between ASIRASHL125 km and ASIRAS-NP. An average 3.2\% percent accumulation difference can be obtained using $5 \mathrm{HL}$ profiles at $50 \mathrm{~km}$ spacing. This finding stands to improve accuracy for radar-derived accumulation rates and serve as a guideline for correcting the wealth of IceBridge radar data.

\section{Conclusions}

Point-based measurements such as ice cores and weather stations provide the basis for current accumulation estimates. Models and interpolation between these points provide spatially continuous estimates of accumulation. Radardetected annual accumulation layers offer a physical observation connecting point-based measurements. Detailed NP density measurements provide accurate radar travel time velocities and exact densities for water-equivalent conversion, improving accuracy of annual accumulation rates from ASIRAS. We report spatially continuous annual accumulation rates from 1959 to 2004 along a $250 \mathrm{~km}$ segment of EGIG. Our ASIRAS-NP rates are not statistically different from EGIG-Ground point measurements spanning 1985-2004. Polar MM5 and RACMO2.3 consistently underestimate accumulation by $17 \%$ along EGIG compared to ASIRAS-NP. MAR underestimates by as much as $16 \%$ and overestimates by $10 \%$. Overall, Regional Climate Models Polar MM5, MAR, and RACMO2.3 succeed in capturing the general trend of accumulation seen by ASIRAS-NP, but they underestimate the total amount of snow. The ASIRASNP observed increases in mean accumulation may relate to increased warming and availability of moisture at higher elevations.
The similarity between ASIRAS and EGIG-Ground demonstrates that the ASIRAS layers, adjusted with NP density, produce accurate estimates of accumulation along a continuous $250 \mathrm{~km}$ segment of the EGIG line. We recognize the challenge of obtaining detailed density measurements and demonstrate the use of simple HL models to derive adequate accumulation estimates in the dry snow region. Using Herron and Langway (1980) profiles at $50 \mathrm{~km}$ intervals produces ASIRAS-HL accumulation rates within $3 \%$ of ASIRAS-NP estimates. High resolution airborne radar systems operated in dry snow regions of ice sheets, such as those onboard Operation IceBridge, calibrated with a minimal number of Herron and Langway (1980) modeled density profiles, may produce accumulation rates within the uncertainty of accumulation best-estimates using detailed density profiles.

\section{Data availability}

The original raw ASIRAS data must be accessed via the European Space Agency's EO Data Access site: https:// earth.esa.int/web/guest/data-access/how-to-access-eo-data/ how-to-access-earth-observation-data-distributed-by-esa (ESA-EarthOnline, 2016), https://directory.eoportal.org/ web/eoportal/airborne-sensors/asiras (ESA-ASIRAS, 2016).

The neutron probe data can be accessed by contacting Elizabeth (Liz) Morris http://www.spri.cam.ac.uk/people/ morris/ (emm36@cam.ac.uk).

See the Assets tab for DOIs for the ASIRAS-NP and ASIRAS-HL accumulation rates and ASCII versions of Table 1, Table 2, and Table A1. 
Appendix A

Table A1. Mean annual ASIRAS-NP accumulation (mw.e.) at T-sites along EGIG.

\begin{tabular}{|c|c|c|c|c|c|c|c|c|c|}
\hline Year & $\mathrm{T} 21$ & $\mathrm{~T} 21 \mathrm{a}$ & $\mathrm{T} 23$ & $\mathrm{~T} 27$ & $\mathrm{~T} 31$ & T35 & T39 & $\mathrm{T} 41$ & $\mathrm{~T} 43$ \\
\hline Lat & 70.54 & 70.59 & 70.62 & 70.78 & 70.91 & 70.98 & 71.04 & 71.08 & 71.12 \\
\hline Lon & -43.03 & -42.79 & -42.58 & -41.54 & -40.64 & -39.55 & -38.46 & -37.92 & -37.32 \\
\hline 2004 & $0.64 \pm 0.01$ & $0.67 \pm 0.01$ & $0.64 \pm 0.01$ & $0.56 \pm 0.01$ & $0.49 \pm 0.01$ & $0.40 \pm 0.01$ & $0.36 \pm 0.01$ & $0.33 \pm 0.01$ & $0.31 \pm 0.01$ \\
\hline 2003 & $0.56 \pm 0.01$ & $0.58 \pm 0.01$ & $0.61 \pm 0.01$ & $0.48 \pm 0.01$ & $0.43 \pm 0.01$ & $0.37 \pm 0.01$ & $0.33 \pm 0.01$ & $0.30 \pm 0.01$ & $0.31 \pm 0.01$ \\
\hline 2002 & $0.39 \pm 0.01$ & $0.41 \pm 0.01$ & $0.39 \pm 0.01$ & $0.38 \pm 0.01$ & $0.38 \pm 0.01$ & $0.34 \pm 0.01$ & $0.30 \pm 0.01$ & $0.32 \pm 0.01$ & $0.35 \pm 0.01$ \\
\hline 2001 & $0.56 \pm 0.01$ & $0.58 \pm 0.01$ & $0.48 \pm 0.01$ & $0.41 \pm 0.01$ & $0.36 \pm 0.01$ & $0.36 \pm 0.01$ & $0.32 \pm 0.01$ & $0.29 \pm 0.01$ & $0.28 \pm 0.01$ \\
\hline 2000 & $0.56 \pm 0.01$ & $0.54 \pm 0.01$ & $0.52 \pm 0.01$ & $0.42 \pm 0.01$ & $0.35 \pm 0.01$ & $0.28 \pm 0.01$ & $0.29 \pm 0.01$ & $0.25 \pm 0.01$ & $0.23 \pm 0.01$ \\
\hline 1999 & $0.49 \pm 0.03$ & $0.41 \pm 0.03$ & $0.52 \pm 0.01$ & $0.54 \pm 0.01$ & $0.47 \pm 0.01$ & $0.46 \pm 0.01$ & $0.39 \pm 0.01$ & $0.38 \pm 0.01$ & $0.37 \pm 0.01$ \\
\hline 1998 & $0.40 \pm 0.01$ & $0.42 \pm 0.01$ & $0.40 \pm 0.01$ & $0.31 \pm 0.01$ & $0.31 \pm 0.01$ & $0.25 \pm 0.01$ & $0.23 \pm 0.01$ & $0.24 \pm 0.01$ & $0.21 \pm 0.01$ \\
\hline 1997 & $0.45 \pm 0.01$ & $0.44 \pm 0.01$ & $0.46 \pm 0.01$ & $0.42 \pm 0.01$ & $0.39 \pm 0.02$ & $0.33 \pm 0.01$ & $0.31 \pm 0.01$ & $0.29 \pm 0.01$ & $0.26 \pm 0.01$ \\
\hline 1996 & $0.50 \pm 0.01$ & $0.51 \pm 0.01$ & $0.50 \pm 0.01$ & $0.46 \pm 0.01$ & $0.47 \pm 0.04$ & $0.47 \pm 0.01$ & $0.44 \pm 0.01$ & $0.39 \pm 0.01$ & $0.41 \pm 0.01$ \\
\hline 1995 & $0.61 \pm 0.02$ & $0.55 \pm 0.02$ & $0.59 \pm 0.01$ & $0.53 \pm 0.02$ & $0.43 \pm 0.03$ & $0.41 \pm 0.01$ & $0.34 \pm 0.01$ & $0.33 \pm 0.01$ & $0.30 \pm 0.02$ \\
\hline 1994 & $0.34 \pm 0.01$ & $0.32 \pm 0.01$ & $0.35 \pm 0.01$ & $0.34 \pm 0.01$ & $0.32 \pm 0.01$ & $0.26 \pm 0.01$ & $0.26 \pm 0.01$ & $0.25 \pm 0.02$ & $0.21 \pm 0.01$ \\
\hline 1993 & $0.36 \pm 0.01$ & $0.36 \pm 0.01$ & $0.34 \pm 0.01$ & $0.28 \pm 0.01$ & $0.27 \pm 0.01$ & $0.23 \pm 0.01$ & $0.23 \pm 0.01$ & $0.23 \pm 0.01$ & $0.25 \pm 0.01$ \\
\hline 1992 & $0.29 \pm 0.01$ & $0.33 \pm 0.01$ & $0.32 \pm 0.01$ & $0.30 \pm 0.01$ & $0.29 \pm 0.01$ & $0.29 \pm 0.01$ & $0.29 \pm 0.01$ & $0.26 \pm 0.01$ & $0.26 \pm 0.01$ \\
\hline 1991 & $0.58 \pm 0.01$ & $0.53 \pm 0.01$ & $0.50 \pm 0.03$ & $0.40 \pm 0.01$ & $0.39 \pm 0.02$ & $0.39 \pm 0.01$ & $0.34 \pm 0.01$ & $0.35 \pm 0.01$ & $0.33 \pm 0.01$ \\
\hline 1990 & $0.44 \pm 0.01$ & $0.46 \pm 0.01$ & $0.49 \pm 0.02$ & $0.46 \pm 0.01$ & $0.42 \pm 0.02$ & $0.39 \pm 0.01$ & $0.36 \pm 0.01$ & $0.34 \pm 0.01$ & $0.33 \pm 0.01$ \\
\hline 1989 & $0.40 \pm 0.01$ & $0.40 \pm 0.01$ & $0.41 \pm 0.01$ & $0.40 \pm 0.01$ & $0.38 \pm 0.01$ & $0.30 \pm 0.01$ & $0.30 \pm 0.01$ & $0.28 \pm 0.01$ & $0.27 \pm 0.01$ \\
\hline 1988 & $0.40 \pm 0.01$ & $0.40 \pm 0.01$ & $0.41 \pm 0.01$ & $0.34 \pm 0.01$ & $0.30 \pm 0.01$ & $0.26 \pm 0.01$ & $0.27 \pm 0.01$ & $0.24 \pm 0.01$ & $0.24 \pm 0.01$ \\
\hline 1987 & $0.39 \pm 0.01$ & $0.39 \pm 0.01$ & $0.38 \pm 0.01$ & $0.33 \pm 0.02$ & $0.34 \pm 0.01$ & $0.33 \pm 0.01$ & $0.28 \pm 0.01$ & $0.28 \pm 0.02$ & $0.26 \pm 0.01$ \\
\hline 1986 & - & - & $0.33 \pm 0.05$ & $0.43 \pm 0.02$ & $0.40 \pm 0.01$ & $0.34 \pm 0.01$ & $0.32 \pm 0.01$ & $0.34 \pm 0.01$ & $0.30 \pm 0.01$ \\
\hline 1985 & - & - & $0.66 \pm 0.08$ & $0.49 \pm 0.02$ & $0.44 \pm 0.01$ & $0.43 \pm 0.01$ & $0.31 \pm 0.01$ & $0.26 \pm 0.01$ & $0.25 \pm 0.01$ \\
\hline 1984 & - & - & $0.47 \pm 0.01$ & $0.42 \pm 0.04$ & $0.32 \pm 0.01$ & $0.26 \pm 0.02$ & $0.27 \pm 0.01$ & $0.27 \pm 0.01$ & $0.28 \pm 0.01$ \\
\hline 1983 & - & - & $0.47 \pm 0.01$ & $0.51 \pm 0.01$ & $0.48 \pm 0.02$ & $0.35 \pm 0.01$ & $0.34 \pm 0.01$ & $0.35 \pm 0.01$ & $0.31 \pm 0.01$ \\
\hline 1982 & - & - & $0.32 \pm 0.01$ & $0.29 \pm 0.03$ & $0.27 \pm 0.02$ & $0.27 \pm 0.01$ & $0.28 \pm 0.01$ & $0.25 \pm 0.01$ & $0.28 \pm 0.01$ \\
\hline 1981 & - & - & $0.41 \pm 0.01$ & $0.33 \pm 0.02$ & $0.29 \pm 0.02$ & $0.27 \pm 0.01$ & $0.21 \pm 0.02$ & $0.22 \pm 0.01$ & $0.20 \pm 0.01$ \\
\hline 1980 & - & - & $0.27 \pm 0.01$ & $0.38 \pm 0.02$ & $0.33 \pm 0.01$ & $0.29 \pm 0.01$ & $0.29 \pm 0.02$ & $0.26 \pm 0.01$ & $0.24 \pm 0.01$ \\
\hline 1979 & - & - & $0.32 \pm 0.01$ & $0.23 \pm 0.02$ & $0.29 \pm 0.01$ & $0.26 \pm 0.01$ & $0.28 \pm 0.02$ & $0.26 \pm 0.01$ & $0.28 \pm 0.01$ \\
\hline 1978 & - & - & $.46 \pm 0.01$ & $0.43 \pm 0.01$ & $0.35 \pm 0.01$ & $0.34 \pm 0.01$ & $0.28 \pm 0.01$ & $0.28 \pm 0.01$ & $0.24 \pm 0.01$ \\
\hline 1977 & - & - & $0.57 \pm 0.01$ & $0.51 \pm 0.01$ & $0.38 \pm 0.01$ & $0.35 \pm 0.01$ & $0.34 \pm 0.01$ & $0.27 \pm 0.02$ & $0.28 \pm 0.01$ \\
\hline 1976 & - & - & $0.40 \pm 0.01$ & $0.39 \pm 0.01$ & $0.38 \pm 0.01$ & $0.37 \pm 0.01$ & $0.28 \pm 0.02$ & $0.31 \pm 0.01$ & $0.24 \pm 0.01$ \\
\hline 1975 & - & - & $0.42 \pm 0.01$ & $0.54 \pm 0.01$ & $0.42 \pm 0.02$ & $0.27 \pm 0.02$ & $0.30 \pm 0.01$ & $0.31 \pm 0.01$ & $0.34 \pm 0.01$ \\
\hline 1974 & - & - & $0.31 \pm 0.01$ & $0.30 \pm 0.01$ & $0.43 \pm 0.01$ & $0.37 \pm 0.01$ & $0.34 \pm 0.01$ & $0.28 \pm 0.01$ & $0.25 \pm 0.01$ \\
\hline 1973 & - & - & $0.33 \pm 0.01$ & $0.31 \pm 0.01$ & $0.29 \pm 0.01$ & $0.26 \pm 0.01$ & $0.24 \pm 0.01$ & $0.23 \pm 0.01$ & $0.26 \pm 0.01$ \\
\hline 1972 & - & - & - & - & $0.32 \pm 0.02$ & $0.33 \pm 0.02$ & $0.28 \pm 0.01$ & $0.31 \pm 0.01$ & $0.31 \pm 0.01$ \\
\hline 1971 & - & - & - & - & $0.32 \pm 0.01$ & $0.31 \pm 0.01$ & $0.26 \pm 0.01$ & $0.25 \pm 0.01$ & $0.25 \pm 0.01$ \\
\hline 1970 & - & - & - & - & $0.28 \pm 0.01$ & $0.28 \pm 0$ & $0.28 \pm 0.01$ & $0.27 \pm 0.01$ & $0.25 \pm 0.01$ \\
\hline 1969 & - & - & - & - & $0.41 \pm 0.01$ & $0.32 \pm 0.01$ & $0.23 \pm 0.01$ & $0.24 \pm 0.01$ & $0.22 \pm 0.01$ \\
\hline 1968 & - & - & - & - & $0.30 \pm 0.01$ & $0.28 \pm 0.01$ & $0.28 \pm 0.01$ & $0.26 \pm 0.01$ & $0.25 \pm 0.01$ \\
\hline 1967 & - & - & - & - & $0.29 \pm 0.01$ & $0.28 \pm 0.01$ & $0.28 \pm 0.01$ & $0.28 \pm 0.01$ & $0.26 \pm 0.01$ \\
\hline 1966 & - & - & - & - & $0.27 \pm 0.01$ & $0.31 \pm 0.02$ & $0.22 \pm 0.01$ & $0.23 \pm 0.01$ & $0.19 \pm 0.01$ \\
\hline 1965 & - & - & - & - & $0.24 \pm 0.01$ & $0.22 \pm 0.01$ & $0.23 \pm 0.01$ & $0.22 \pm 0.01$ & $0.23 \pm 0.01$ \\
\hline 1964 & - & - & - & - & $0.34 \pm 0.01$ & $0.35 \pm 0.01$ & $0.34 \pm 0.01$ & $0.34 \pm 0.01$ & $0.28 \pm 0.01$ \\
\hline 1963 & - & - & - & - & $0.31 \pm 0.01$ & $0.31 \pm 0.01$ & $0.29 \pm 0.01$ & $0.29 \pm 0.01$ & $0.29 \pm 0.01$ \\
\hline 1962 & - & - & - & - & $0.24 \pm 0.01$ & $0.24 \pm 0.01$ & $0.20 \pm 0.01$ & $0.23 \pm 0.01$ & $0.23 \pm 0.01$ \\
\hline 1961 & - & - & - & - & $0.23 \pm 0.01$ & $0.24 \pm 0.01$ & $0.24 \pm 0.01$ & $0.25 \pm 0.01$ & $0.23 \pm 0.01$ \\
\hline 1960 & - & - & - & - & $0.28 \pm 0.01$ & $0.28 \pm 0.01$ & $0.27 \pm 0.01$ & $0.27 \pm 0.01$ & $0.24 \pm 0.01$ \\
\hline 1959 & - & - & - & - & $0.34 \pm 0.01$ & $0.35 \pm 0.01$ & $0.32 \pm 0.01$ & $0.33 \pm 0.01$ & $0.30 \pm 0.01$ \\
\hline
\end{tabular}


Table A2. Pearson's correlation coefficients for EGIG-Ground, ASIRAS-NP, and RCM accumulation rates. Number of rates compared appears in parentheses.

\begin{tabular}{lccccc}
\hline Paired & T21 & T27 & T31 & T41 & T43 \\
\cline { 2 - 6 } & \multicolumn{5}{c}{ Pearson's $R$} \\
\hline ASIRAS-NP and EGIG-Ground & $0.46(16)$ & $0.19(21)$ & $0.21(24)$ & $0.42(27)$ & $0.56(13)$ \\
ASIRAS-NP and Polar MM5 & $0.55(18)$ & $0.53(32)$ & $0.40(46)$ & $0.56(46)$ & $0.49(46)$ \\
ASIRAS-NP and MAR & $0.37(18)$ & $0.32(32)$ & $0.32(46)$ & $0.40(46)$ & $0.41(46)$ \\
ASIRAS-NP and RACMO2.3 & $0.24(18)$ & $0.35(32)$ & $0.28(46)$ & $0.41(46)$ & $0.40(46)$ \\
\hline
\end{tabular}

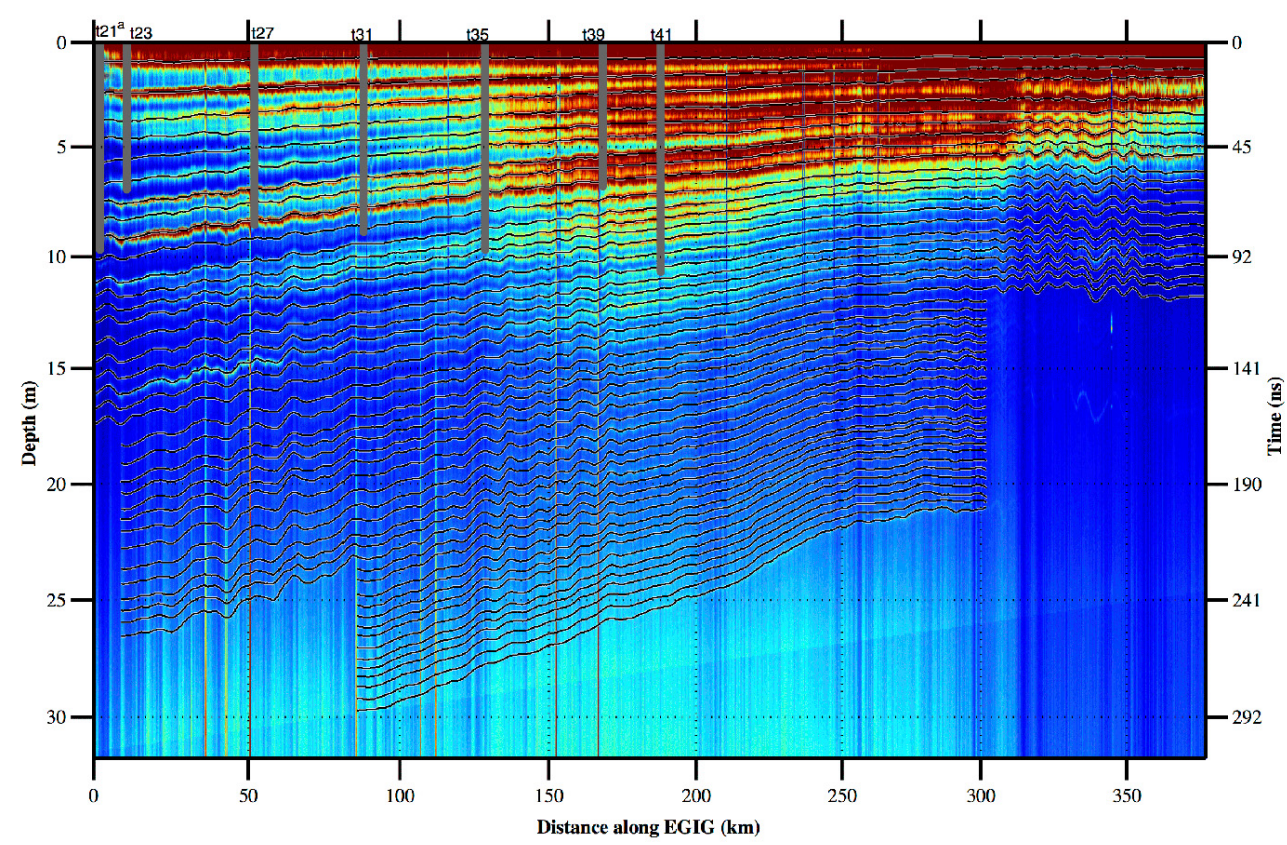

Figure A1. ASIRAS radargram of the 47 traced internal reflection horizons (IRHs), or layers, down to $30 \mathrm{~m}$ depth. The uppermost layer represents the 2005 accumulation year. The deepest layer represents 1959. Distance along EGIG corresponds with T21 in Fig. 1, with 0 km starting at $2700 \mathrm{~m}$ on the western slope and extending beyond $350 \mathrm{~km}$ where layer visibility decreases on the eastern slope of the Greenland Ice Sheet. High coastal accumulation rates, evident from thicker western layers from 0 to $50 \mathrm{~km}$, gradually thin with increasing elevation and orographic deposition of accumulation approaching the ice divide at $210 \mathrm{~m}$ distance. Topographic effects related to local surface features (described by Black and Budd, 1964) may explain layer undulations. Vertical gray lines indicate the position and depth of Morris and Wingham (2011) NP density measurements. 
Acknowledgements. This work was supported by the European Space Agency (ESA) as a part of the CryoSat program and by National Aeronautics and Space Administration (NASA) Grants NNX10AP04G and NNX10AG22G. The work of Veit Helm was funded by the German Federal Ministry of Economics and Technology (Grant 50EE1331). We thank all team members involved in the CryoVex 2006 campaign. We are especially grateful to the in situ calibration and validation team for their efforts collecting detailed neutron-probe data. We thank reviewers Lora Koenig, Ginny Catania, two anonymous reviewers, and editor Marco Tedesco for their comments and handling of the manuscript.

Edited by: M. Tedesco

Reviewed by: L. Koenig and two anonymous referees

\section{References}

Anklin, M. and Stauffer, B.: Pattern of annual snow accumulation along a west Greenland flow lone: no significant change observed during recent decades, Tellus B, 46, 294-303, 1994.

Arcone, S., Spikes, V., Hamilton, G., and Mayewski, P. A.: Stratigraphic continuity in $400 \mathrm{MHz}$ short-pulse radar profiles of firn in West Antarctica, Ann. Glaciol., 39, 195-200, 2004.

Arcone, S., Spikes, V., and Hamilton, G.: Stratigraphic variation within polar firn caused by differential accumulation and ice flow: interpretation of a $400 \mathrm{MHz}$ short-pulse radar profile from West Antarctica, J. Glaciol., 51, 407-422, 2005.

Bales, R. C., McConnell, J. R., Mosley-Thompson, E., and Csatho, B.: Accumulation over the Greenland ice sheet from historical and recent records, J. Geophys. Res.-Atmos., 106, 3381333825, 2001.

Bales, R. C., Guo, Q., Shen, D., McConnell, J., Du, G., Burkhart, J. F., Spikes, V., Hanna, E., and Cappelen, J.: Annual accumulation for Greenland updated using ice core data developed during 2000-2006 and analysis of daily coastal meteorological data, J. Geophys. Res., 114, D06116, doi:10.1029/2008JD011208, 2009.

Banta, J. and McConnell, J. R.: Annual accumulation over recent centuries at four sites in central Greenland, J. Geophys. Res., 112, D10114, doi:10.1029/2006JD007887, 2007.

Benson, C.: Stratigraphic studies in the snow and firn of the Greenland ice sheet., Research Report 70, U.S. Army Snow, Ice and Permafrost Research Establishment, Corps of Engineers, 1962.

Black, H. and Budd, W.: Accumulation in the region of Wilkes, Wilkes Land, Antarctica, J. Glaciol., 5, 3-15, 1964.

Box, J. E., Bromwich, D. H., and Bai, L. S.: Greenland ice sheet surface mass balance 1991-2000: application of Polar MM5 mesoscale model and in situ data, J. Geophys. Res., 109, D16105, doi:10.1029/2003JD004451, 2004.

Bromwich, D. H., Chen, Q. S., Bai, L. S., Cassano, E., and Li, Y.: Modeled precipitation variability over the Greenland ice sheet, J. Geophys. Res., 106, 33891-33908, 2001.

Burgess, E., Forster, R. R., Box, J. E., Mosley-Thompson, E., Bromwich, D. H., Bales, R. C., and Smith, L.: A spatially calibrated model of annual accumulation rate on the Greenland Ice Sheet (1958-2007), J. Geophys. Res., 115, F02004, doi:10.1029/2009JF001293, 2010.
Cullen, R.: CryoVEx Airborne Data Products Description, ASIRAS 2.6.1, European Space Agency, ESTEC, Noordwijk, Netherlands, 2010.

Dansgaard, W.: Frozen Annals: Greenland Ice Sheet Research, Aage V. Jenkins Fonde (Denmark), 1st Edn., available at: http://www.nbi.ku.dk/english/www/willi/dansgaard/ tilbage-til-groenland/ (last access: 12 August 2015), 2004.

de la Peña, S., Nienow, P., Shepherd, A., Helm, V., Mair, D., Hanna, E., Huybrechts, P., Guo, Q., Cullen, R., and Wingham, D.: Spatially extensive estimates of annual accumulation in the dry snow zone of the Greenland Ice Sheet determined from radar altimetry, The Cryosphere, 4, 467-474, doi:10.5194/tc-4-467-2010, 2010.

Eisen, O., Frezzotti, M., Genthon, C., Isaksson, E., Magand, O., van den Broeke, M. R., Dixon, D., Ekaykin, A., Holmlund, P., Kameda, T., Karlöf, L., Kaspari, S., Lipenkov, V., Oerter, H., Takahashi, S., and Vaughan, D. G.: Ground-based measurements of spatial and temporal variability of snow accumulation in East Antarctica, Rev. Geophys., 46, RG2001, doi:10.1029/2006RG000218, 2008.

ESA-ASIRAS, EO Portal Directory: ASIRAS (Airborne SAR/Interferometric Radar System), https://directory.eoportal. org/web/eoportal/airborne-sensors/asiras, European Space Agency, Earth Observation Ground Segment Department User Services and Mission Planning Office, Frascati (Rome) Italy, 2016.

ESA-EarthOnline: How to access EO data, https://earth. esa.int/web/guest/data-access/how-to-access-eo-data/ how-to-access-earth-observation-data-distributed-by-esa,

European Space Agency, Earth Observation Ground Segment Department User Services and Mission Planning Office, Frascati (Rome) Italy, 2016.

Fischer, H., Wagenbach, D., Laternser, M., and Haeberli, W.: Glaciometerological and isotopic studies along the EGIG line, central Greenland ice sheet, J. Glaciol., 41, 515-527, 1995.

Hawley, R. L., Morris, E. M., Cullen, R., Nixdorf, U., Shepherd, A. P., and Wingham, D. J.: ASIRAS airborne radar resolves internal annual layers in the dry-snow zone of Greenland, Geophys. Res. Lett., 33, L04502, doi:10.1029/2005GL025147, 2006.

Hawley, R. L., Morris, E. M., and McConnell, J.: Intruments and methods rapid techniques for determining annual accumulation applied at Summit, Greenland, J. Glaciol., 54, 839-845, 2008.

Hawley, R. L., Courville, Z., Kehrl, L., Lutz, E., Osterberg, E., Overly, T., and Wong, G.: Recent accumulation variability in northwest Greenland from ground-penetrating radar and shallow cores along the Greenland Inland Traverse, J. Glaciol., 60, 375382, 2014

Helm, V., Rack, W., Cullen, R., Neinow, P., Mair, D., Parry, V., and Wingham, D. J.: Winter accumulation in the percolation zone of Greenland measured by airborne radar altimeter, Geophys. Res. Lett., 34, L06501, doi:10.1029/2006GL029185, 2007.

Herron, M. and Langway Jr., C.: Firn densification: an empirical model, J. Glaciol., 25, 373-385, 1980.

IPCC: Climate Change 2014 Synthesis Report, edited by: Pachauri, K., Meyer, L., and core writing team, Intergovernmental Panel on Climate Change, IPCC Secretariat, Geneva, Switzerland, 2014.

Kovacs, A., Gow, A. J., and Morey, R. M.: The in-situ dielectric constant of polar firn revisted, Cold Reg. Sci. Technol., 23, 245256, 1995. 
McConnell, J. R., Mosley-Thompson, E., Bromwich, D. H., Bales, R. C., and Kyne, J. D.: Interannual variations of snow accumulation on the Greenland Ice Sheet (1985-1996): new observations versus model predictions, J. Geophys. Res.-Atmos., 105, 4039-4046, 2000.

McConnell, J. R., Lamorey, G., Hanna, E., Mosley-Thompson, E., Bales, R. C., Belle-Oudry, D., and Kyne, J. D.: Annual net snow accumulation over southern Greenland from 1975 to 1998, J. Geophys. Res., 106, 33827-33837, 2001.

Medley, B., Joughin, I., Das, S., Steig, E. J., Conway, H., Gogineni, S., Criscitiello, A., McConnell, J., Smith, B., van den Broeke, M. R., Lenaerts, J., Bromwich, D., and Nicolas, J.: Airborneradar and ice-core observations of annual snow accumulation over Thwaites Glacier, West Antarctica confirm the spatiotemporal variability of global and regional atmospheric models, Geophys. Res. Lett., 40, 3649-3654, 2013.

Medley, B., Joughin, I., Smith, B. E., Das, S. B., Steig, E. J., Conway, H., Gogineni, S., Lewis, C., Criscitiello, A. S., McConnell, J. R., van den Broeke, M. R., Lenaerts, J. T. M., Bromwich, D. H., Nicolas, J. P., and Leuschen, C.: Constraining the recent mass balance of Pine Island and Thwaites glaciers, West Antarctica, with airborne observations of snow accumulation, The Cryosphere, 8, 1375-1392, doi:10.5194/tc-8-13752014, 2014.

Merlivat, L., Lorius, C., Ravoire, J., and Vergnaud, J.: Tritium and deuterium content of the snow in Groenland, Earth Planet. Sc. Lett., 19, 235-240, 1973.

Miége, C., Forster, R. R., Box, J. E., Burgess, E. W., McConnell, J. R., Pasteris, D. R., and Spikes, V. B.: Southeast Greenland high accumulation rates derived from firn cores and groundpenetrating radar, Ann. Glaciol., 54, 322-332, 2013.

Morris, E. M.: A theoretical analysis of the neutron-scattering method for measuring snow and ice density, J. Geophys. Res., 113, F03019, doi:10.1029/2007JF000962, 2008.

Morris, E. M. and Cooper, J.: Density measurements in ice boreholes using neutron scattering, J. Glaciol., 49, 599-604, 2003.

Morris, E. M. and Wingham, D. J.: The effect of fluctuations in surface density, accumulation and compaction on elevation change rates along the EGIG line, central Greenland, J. Glaciol., 57, 416-430, 2011.

Morris, E. M. and Wingham, D. J.: Densification of polar snow: measurements, modeling, and implications for altimetry, J. Geophys. Res.-Earth, 119, 349-365, 2014.
Mosley-Thompson, E., McConnell, J. R., Bales, R. C., Lin, P. N., Steffen, K., Thompson, L. G., Edwards, R., and Bathke, D.: Local to regional-scale variability of annual net accumulation on the Greenland ice sheet from PARCA cores, Journal Of Geophysical Research-Atmospheres, 106, 33839-33851, 2001.

Noël, B., van de Berg, W. J., van Meijgaard, E., Kuipers Munneke, P., van de Wal, R. S. W., and van den Broeke, M. R.: Evaluation of the updated regional climate model RACMO2.3: summer snowfall impact on the Greenland Ice Sheet, The Cryosphere, 9, 1831-1844, doi:10.5194/tc-9-1831-2015, 2015.

NSIDC: GISP2 B-Core Density. The Greenland Summit Ice Cores CD-ROM, Tech. rep., National Snow and Ice Data Center, University of Colorado, Boulder, 1997.

Renaud, A., Schumacher, E., Hughes, B., Oeschger, H., and Mühlemann, C.: Tritium variations in Greenland Ice, J. Geophys. Res., 68, p. 3783, doi:10.1029/JZ068i013p03783, 1963.

Rignot, E., Box, J., and Burgess, E.: Mass balance of the Greenland ice sheet from 1958 to 2007, Geophys. Res. Lett., 35, L20502, doi:10.1029/2008GL035417, 2008.

Simonsen, S., Stenseng, S., Aðalgeirsdóttir, G., Fausto, R., Hvidberg, C. S., and Lucas-Picher, P.: Assessing a multilayered dynamic firn-compaction model for Greenland with ASIRAS radar measurements, J. Glaciol., 59, 545-558, 2013.

Spikes, V., Hamilton, G., Arcone, S., Kaspari, S., and Mayewski, P.: Variability in accumulation rates from GRP profiling on the West Antarctic plateau, Ann. Glaciol., 39, 238-244, 2004.

Steffen, K. and Box, J.: Surface climatology of the Greenland ice sheet: Greenland Climate Network 1995-1999, J. Geophys. Res., 106, 33951-33964, 2001.

Stenseng, L., Hvidegaard, S., Skourup, H., Forsberg, R., Andersen, C., Hanson, S., Cullen, R., and Helm, V.: Airborne Lidar and Radar Measurements In and Around Greenland CryoVEx 2006, Tech. rep., Danish National Space Institute, Copenhagen, Denmark, 2007.

Tedesco, M., Fettweis, X., and Alexander, P.: MAR v3.2 regional climate model data for Greenland (1958-2013). UCAR/NCAR CISL - ACADIS., doi:10.5065/D6JH3J7Z, 2015.

Wessel, P., Smith, W. H. F., Scharroo, R., Luis, J. F., and Wobbe, F.: Generic Mapping Tools: Improved version released, EOS Trans. AGU, 94, 409-410, 2013.

Zwally, H. J. and Li, J.: Seasonal and interannual variations of firn densification and ice-sheet surface elevation at the Greenland summit, J. Glaciol., 48, 199-207, 2002. 